\title{
The effect of hypoxia on myogenic differentiation and multipotency of the skeletal muscle-derived stem cells in mice
}

\author{
Mohamed I. Elashry ${ }^{*}$ (D), Mebrie Kinde ${ }^{1}$, Michele C. Klymiuk ${ }^{1}$, Asmaa Eldaey ${ }^{3}$, Sabine Wenisch ${ }^{2}$ and \\ Stefan Arnhold ${ }^{1}$
}

\begin{abstract}
Background: Skeletal muscle-derived stem cells (SC) have become a promising approach for investigating myogenic differentiation and optimizing tissue regeneration. Muscle regeneration is performed by SC, a self-renewal cell population underlying the basal lamina of muscle fibers. Here, we examined the impact of hypoxia condition on the regenerative capacity of SC either in their native microenvironment or via isolation in a monolayer culture using ectopic differentiation inductions. Furthermore, the effect of low oxygen tension on myogenic differentiation protocols of the myoblasts cell line C2C12 was examined.
\end{abstract}

Methods: Hind limb muscles of wild type mice were processed for both SC/fiber isolation and myoblast extraction using magnetic beads. SC were induced for myogenic, adipogenic and osteogenic commitments under normoxic $\left(21 \% \mathrm{O}_{2}\right)$ and hypoxic $\left(3 \% \mathrm{O}_{2}\right)$ conditions. SC proliferation and differentiation were evaluated using histological staining, immunohistochemistry, morphometric analysis and RT-qPCR. The data were statistically analyzed using ANOVA.

Results: The data revealed enhanced SC proliferation and motility following differentiation induction after $48 \mathrm{~h}$ under hypoxia. Following myogenic induction, the number of undifferentiated cells positive for Pax 7 were increased at $72 \mathrm{~h}$ under hypoxia. Hypoxia upregulated MyoD and downregulated Myogenin expression at day-7 post-myogenic induction. Hypoxia promoted both SC adipogenesis and osteogenesis under respective induction as shown by using Oil Red $O$ and Alizarin Red S staining. The expression of adipogenic markers; peroxisome proliferator activated receptor gamma (PPARY) and fatty acid-binding protein 4 (FABP4) were upregulated under hypoxia up to day 14 compared to normoxic condition. Enhanced osteogenic differentiation was detected under hypoxic condition via upregulation of osteocalcin and osteopontin expression up to day 14 as well as, increased calcium deposition at day 21. Hypoxia exposure increases the number of adipocytes and the size of fat vacuoles per adipocyte compared to normoxic culture. Combining the differentiation medium with dexamethasone under hypoxia improves the efficiency of the myogenic differentiation protocol of $\mathrm{C} 2 \mathrm{C} 12$ by increasing the length of the myotubes.

Conclusions: Hypoxia exposure increases cell resources for clinical applications and promotes SC multipotency and thus beneficial for tissue regeneration.

Keywords: Muscle Stem cells, Proliferation, Differentiation, Multipotency, Hypoxia

*Correspondence: Mohammed.Elashry@vetmed.uni-giessen.de ${ }^{1}$ Institute of Veterinary Anatomy, Histology and Embryology, JustusLiebig-University of Giessen, Frankfurter Str. 98, 35392 Giessen, Germany Full list of author information is available at the end of the article

\section{Introduction}

Muscle-derived stem cells (SC) have received considerable attention to investigate myogenesis, tissue regeneration and stem cell therapy. SC are known as satellite cells, original author(s) and the source, provide a link to the Creative Commons licence, and indicate if changes were made. The images or other third party material in this article are included in the article's Creative Commons licence, unless indicated otherwise in a credit line to the material. If material is not included in the article's Creative Commons licence and your intended use is not permitted by statutory regulation or exceeds the permitted use, you will need to obtain permission directly from the copyright holder. To view a copy of this licence, visit http://creativecommons.org/licenses/by/4.0/. The Creative Commons Public Domain Dedication waiver (http://creativecommons.org/publicdomain/zero/1.0/) applies to the data made available in this article, unless otherwise stated in a credit line to the data. 
a self-renewing cell population beneath the basal lamina of muscle fibers [1]. SC are the main cell population responsible for muscle regeneration. Several evidence have reported the negative effect of muscle degeneration on the quality of life as shown in muscular dystrophy and sarcopenia; an age-related loss of muscle mass $[2,3]$. It was documented that $20-25$ per 100,000 persons suffer from muscular dystrophies worldwide [4] and $25 \%$ and $40 \%$ of individuals older than 70 and 80 are more susceptible to sarcopenia respectively [3]. So far, muscle degenerative diseases have no convincing cure [5-7]. The current approaches are more likely to limit progression of muscle loss [3]. Stem cells offer a great potential for the treatment of incurable diseases which cannot be handled by conventional medicine [8-11]. Additionally, tracking $\mathrm{SC}$ performance in the course of myogenic differentiation either as single cells cultivated in a monolayer or when the cells remain in contact with the muscle fiber do not only facilitate the understanding of the regenerative process but also optimize the microenvironment in vitro to mimic in vivo conditions [12-14].

SC are quiescent under normal conditions [1, 15-17]. Up on muscle injury, the cells enter cyclic proliferation with the expression of MyoD to form sufficient myoblasts that either differentiate to restore the myonuclear loss in the preexisting myofibers or form new myofibers [14-19]. Cell proliferation and differentiation are orchestrated by myogenic regulatory elements including Pax7, MyoD, Myf5, Myogenin and MRF4 expression [20]. Quiescent SC are positive for Pax7, an essential factor for their maintenance and self-renewal [21, 22]. Committed myoblasts exit from the cell cycle by downregulation of Pax7, and upregulation of Myogenin and MRF4 expression [20, 23]. Meanwhile, MyoD regulates the transition from undifferentiated myogenic precursors to myoblasts, while Myogenin is involved in myoblasts fusion to form multinucleated myofibers [24]. At the end of myogenesis, Myogenin initiates the expression of the contractile elements particularly myosin heavy chain (MHC) proteins [23]. On the other hand, SC showed commitments into adipogenic and osteogenic fate using specific inducers [25].

For effective clinical application, an in vitro expansion and characterization of a suitable SC population is required [2]. However, myoblasts expansion in culture is very much influenced by factors in the culture condition $[26,27]$. Oxygen is one of the basic components of the microenvironment that plays an important role for cellular metabolism, growth and differentiation [28, 29]. A large body of evidence have shown that hypoxia (HX) enhanced proliferation and differentiation in primary isolated myoblasts in mice [30], rat [31] and bovine [29]. Although the physiological oxygen concentration within the adult skeletal muscle tissue is almost $3.8 \%$, most of the in vitro studies were carried out under $21 \%$ oxygen which is by far higher than the endogenous requirement in the cellular microenvironment [32]. An abundance of evidence indicate that alteration of the oxygen levels can modulate the regenerative capacity of stem cells in vitro [29, 33]. Furthermore, the composition of the culture components can also influence the differentiation potential of myoblasts [22]. Most of the previous studies have been generated on isolated SC in a monolayer culture, whereas SC have been removed from their natural niche. Furthermore, a detailed report investigating the effect of $\mathrm{HX}$ on the myogenic differentiation (MD) and multipotency of SC are not fully elucidated. Thus, it is essential to dissect the effect of $\mathrm{HX}$ on SC either in their native niche mimicking the physiological microenvironment or even after isolating SC as monolayer culture condition. Furthermore, it is important to examine the MD protocol under optimized $\mathrm{O}_{2}$ condition in vitro before further clinical application. Thus, the present study aimed to evaluate the effects of $\mathrm{HX}$ on the viability, proliferation, and multipotency of SC as well as, to assess the efficiency of the MD protocols under HX compared with normoxia (NX). The data revealed enhanced cell viability, cell motility along the muscle fiber and proliferation capacity under 3\% HX that facilitate in vitro reproducibility of SC before clinical applications. We show impaired MD under HX due to failure of cell withdrawal from cyclic division and terminal differentiation. We provide evidence of promoted adipogenesis and osteogenesis under HX suggesting that targeting $\mathrm{HX}$ might be a candidate for improving bone regeneration. We found that adding dexamethasone to the myogenic protocol overcomes the negative effect of HX on myogensis, and it could be an approach to improve muscle regeneration. Taken together, our data reveal a positive effect of $\mathrm{HX}$ on SC proliferation, motility and multipotency. Thus, optimized HX exposure could be beneficial not only to improve cell resources before transplantation but also to promote multipotential differentiation of muscle stem cells to fat and bone formation.

\section{Materials and methods \\ Cell culture \\ Isolation of SC with or without intact muscle fiber}

Single muscle fibers were generated from $M$. extensor digitorum longus of mice $(\mathrm{n}=6)$ as previously reported [34, 35]. All husbandry and experimental procedures were approved by the institutional ethics committee and the Regierungspräsidium Gießen (GI 20/10 Nr. 105/2014). Briefly, muscles were isolated with both intact tendons then were digested in $0.2 \%$ collagenase IV (Biochrome, Germany) in Dulbecco's modified Eagle's medium (DMEM, Gibco, Germany) with $1 \%$ penicillin / 
streptomycin (P/S, Gibco, Germany) at $37^{\circ} \mathrm{C}$ for $90 \mathrm{~min}$. SC were extracted from hind limb muscles including $M$. tibialis anterior, M. gastrocnemius and M. soleus. Muscles were washed in cold PBS containing $1 \% \mathrm{P} / \mathrm{S}$ three times for 5 min each then were digested in $0.1 \%$ collagenase IV in DMEM supplemented with $1 \% \mathrm{P} / \mathrm{S}$ at $37{ }^{\circ} \mathrm{C}$ for $45 \mathrm{~min}$ with shaking. The homogenates were centrifuged at $2000 \times \mathrm{g}$ for $5 \mathrm{~min}$. Supernatants were discarded and pellets were suspended in $2 \%$ fetal calf serum (FCS, Biocell) and then were filtered in $70-\mu \mathrm{m}$ cell strain. Filtrates were centrifuged at $2000 \times \mathrm{g}$ for $10 \mathrm{~min}$. The cell pellets were suspended in fresh $2 \%$ FCS/DMEM. Selection of SC based on surface markers including CD44, CD90 and $\alpha 7$-integrin expression was performed using magnetic beads as previously reported from our group $[36,37]$. Briefly, $10 \mu \mathrm{L}$ of goat anti mouse IgG magnetic bead solution was incubated with 5-10 $\mu \mathrm{g}$ of mouse CD90, CD44 (1:50, DSHB) and $\alpha 7$ integrin (1:50, Santa Cruz) primary antibodies in $5 \% \mathrm{FCS} / \mathrm{PBS}$ with at $4{ }^{\circ} \mathrm{C}$ for $1 \mathrm{~h}$. After three successive washing in PBS, $1 \times 10^{7}$ cells were incubated with the antibodies beads mixture at $4{ }^{\circ} \mathrm{C}$ for $30 \mathrm{~min}$. Selection of beads-coated cells was carried out using a magnetic field. Harvested cells were washed in PBS and then were characterized using immunohistochemistry and PCR.

\section{C2C12 myoblasts}

The Mouse myoblasts $\mathrm{C} 2 \mathrm{C} 12$ cell line is a subclone of $\mathrm{C} 2$ myoblasts originally isolated from thigh muscles of eight weeks-old mice as previously reported $[38,39]$. The cells were purchased from American Type Culture Collection (ATCC, Germany). Cells were thawed at $37{ }^{\circ} \mathrm{C}$ in a water bath and then were expanded in growth medium (GM) composed of DMEM containing $4.5 \mathrm{~g} / \mathrm{mL}$ D-glucose, L-glutamine and pyruvate (Gibco, Germany) supplemented with $10 \%$ FCS and $1 \% \mathrm{P} / \mathrm{S}$ at $37{ }^{\circ} \mathrm{C}$ under standard culture condition. Upon $60 \%$ confluency, cells were detached from the culture flasks using TrypLE ${ }^{\mathrm{TM}}$ express (Gibco, Denmark) and were counted using a hemocytometer under inverted phase contrast microscope. The cells were either seeded in plates or passaged based on the experimental setup.

\section{Assessment of cell viability}

MTT (3-(4, 5-Dimethylthiazol-2-yl)-2, 5-Dimethyltetrazolium Bromide) assay measures the metabolic activity of cells that indicates the number of viable cells. C2C12 mouse myoblasts were seeded in 24-well culture plates at the rate of $1 \times 10^{4}$ cells/ well in GM. Cells were incubated under both NX $\left(21 \% \mathrm{O}_{2}\right)$ and HX $\left(3 \% \mathrm{O}_{2}\right)$ for 1,4 , and 7 days. Cells were provided with fresh medium every two days. Furthermore, cells were incubated with $0.5 \mathrm{mg} / \mathrm{mL}$ MTT (Sigma-Aldrich, Germany) at $37{ }^{\circ} \mathrm{C}$ for $2 \mathrm{~h}$. MTT solution was discarded, and the cells were incubated with $200 \mu \mathrm{L} /$ well of dimethyl sulfoxide for $10 \mathrm{~min}$ with shaking at room temperature (RT). Lysates were pipetted in triplicates into a 96-well microplates. The absorbance was measured at $570 \mathrm{~nm}$ using a microplate reader (Tecan, Switzerland).

\section{Sulforhodamine B assay}

Sulforhodamine B (SRB) assay semi-quantifies the amount of cellular protein contents which is considered as a proportional indicator to the cells number [40]. Briefly, $1 \times 10^{4}$ cells/well were seeded in 24 -well plates in GM at $37{ }^{\circ} \mathrm{C}$ and $5 \% \mathrm{CO}_{2}$ under $\mathrm{NX}$ and $\mathrm{HX}$ conditions. Cells were provided with fresh medium every two day. Cells were fixed with $4 \%$ paraformaldehyde (PFA, Roth, Germany) for $10 \mathrm{~min}$ at RT at days 1, 4, and 7. Cells were incubated with $0.4 \%$ SRB sodium salt (Sigma-Aldrich, Germany) diluted in 1\% acetic acid (Merck, Germany) for $10 \mathrm{~min}$ at RT. Non-buffered Tris solution $(10 \mathrm{mM}, \mathrm{pH} 10$, Sigma-Aldrich, Germany) was added into each well and was incubated for $30 \mathrm{~min}$ at RT to dissolve the bounded SRB. The solution was transferred into a 96-well plate, and the absorbance was measured at $565 \mathrm{~nm}$ using the microplate reader (Tecan, Switzerland).

\section{Colony forming unit assay}

The colony forming unit assay was performed to evaluate the proliferative capacities of $\mathrm{C} 2 \mathrm{C} 12$ myoblasts following HX exposure. C2C12 myoblasts were seeded in $7 \mathrm{~mL}$ of GM per T-25 flasks at seeding densities of $1 \times 10^{2}$, $5 \times 10^{2}, 1 \times 10^{3}$ and $5 \times 10^{3}$ cell per flask. Cells were incubated under both NX and HX culture conditions at $37{ }^{\circ} \mathrm{C}$ for seven days with medium change every two days. Cells were fixed with $4 \%$ PFA for $10 \mathrm{~min}$ at RT then were stained with $5 \mathrm{mg} / \mathrm{mL}$ crystal violet (Roth, Germany) diluted in $2 \%$ ethanol (Roth, Germany) for $8 \mathrm{~min}$. Stained cells were washed twice for $10 \mathrm{~min}$ using distilled water and were left to dry overnight at RT. The number of colonies were counted via the inverted light microscope equipped with digital camera; however, the size of colonies $\left(\mu \mathrm{m}^{2}\right)$ was measured using ImageJ software.

\section{Induction of multipotential differentiation}

SC were seeded either with intact muscle fiber (15-20 fibers/well) or isolated myoblasts $1 \times 10^{4}$ cells/well in triplicates $(n=6)$ in 24-well culture plates. In the latter, the monolayer was allowed to expand in GM for $48 \mathrm{~h}$ before induction. Cells were divided into two experimental groups cultivated under NX and HX conditions using oxygen tension controlled chamber (Labortect Incubator C16, Göttingen, Germany). The differentiation was performed using MD medium consisting of $4.5 \mathrm{~g} / \mathrm{L}$ glucose DMEM supplemented with $2 \%$ horse serum (Millipore, 
Darmstadt, Germany), $2.5 \mathrm{ng} / \mathrm{mL}$ human Fibroblast Growth Factor (Invitrogen) and 1\% sodium pyruvate (Sigma-Aldrich, Germany) up to 14 days. Multipotential differentiation was carried out using either adipogenic differentiation medium (AD) composed of $4.5 \mathrm{mg} / \mathrm{mL}$ glucose DMEM supplemented with 5\% FCS, $1 \mu \mathrm{M}$ dexamethasone (Sigma-Aldrich), $5 \mu \mathrm{g} / \mathrm{mL}$ Insulin-transferrin-selenium (ITS, Sigma-Aldrich, Germany) and $5 \mu \mathrm{M}$ Rosiglitazone (Sigma-Aldrich, Germany) or osteogenic differentiation medium (OD) contained $1 \mathrm{mg} / \mathrm{mL}$ glucose DMEM supplemented with 5\% FCS, $0.1 \mu \mathrm{M}$ dexamethasone, $250 \mu \mathrm{M}$ ascorbic acid (Sigma-Aldrich) and $10 \mathrm{mM}$ $\beta$-glycerophosphate (Fluka, Germany). Non-induced cells were kept in basal medium (BM) containing 5\% FCS in DMEM and $1 \% \mathrm{P} / \mathrm{S}$ were considered controls. SC/fibers were allowed to differentiate up to $72 \mathrm{~h}$ (Additional file 1 : Video S1), whereas extracted myoblasts for monolayer culture were differentiated in AD and OD medium up to 21 days.

\section{Myogenic differentiation protocols}

To assess the effect of HX on the efficiency of the MD protocol, $\mathrm{C} 2 \mathrm{C} 12$ differentiation was performed using modified MD protocols. Briefly, C2C12 cells were seeded in 24-well culture plates at a rate of $1 \times 10^{4}$ cells per well in GM and were incubated at $37^{\circ} \mathrm{C}$ in $5 \% \mathrm{CO}_{2}$ and $21 \%$ oxygen concentration. Up to $60-70 \%$ confluency, MD was induced using MD medium supplemented with either of the following elements; $1 \mathrm{mM}$ dexamethasone, $5 \mathrm{ng} / \mathrm{mL}$ transforming growth factor beta (TGF $\beta$ ) (Sigma-Aldrich, Germany), $1 \mathrm{mg} / \mathrm{mL}$ insulin, $0.57 \mathrm{mg} / \mathrm{mL}$ transferrin and $0.5 \mu \mathrm{g} / \mathrm{mL}$ sodium selenite (ITS). The cells were allowed to differentiate under NX and HX conditions for evaluation at day- 4 and day-14 post-induction.

\section{Immunohistochemistry}

$\mathrm{SC} /$ fibers cultivated in MD, AD and OD medium under both NX and HX conditions were fixed at $48 \mathrm{~h}$ and $72 \mathrm{~h}$ in $4 \%$ PFA for $10 \mathrm{~min}$ at RT. The cells were washed twice in PBS for $5 \mathrm{~min}$ each and then were permeabilized in a buffer composed of $20 \mathrm{mM}$ Hepes, $300 \mathrm{mM}$ sucrose, $50 \mathrm{mM} \mathrm{NaCl}, 3 \mathrm{mM} \mathrm{MgCl}$ and $0.5 \%$ Triton $^{\text {TM }} \mathrm{X}-100$ (pH 7, Calbiochem GmbH, Germany) for $15 \mathrm{~min}$. The cells were blocked in a buffer containing 5\% FCS diluted in PBS, $0.05 \%$ Triton $^{\mathrm{TM}} \mathrm{X}-100$ for $30 \mathrm{~min}$. The cells were incubated with mouse anti-Pax7 (1:30, DSHB, USA), MyoD (1:100, BD Biosciences) and Myogenin (1:30, DSHB, USA) primary antibodies at $4{ }^{\circ} \mathrm{C}$ overnight. The cells were washed for $1 \mathrm{~h}$ with the blocking buffer then were incubated with goat anti-mouse IgG Cy3 and goat anti-mouse fluorescent isothiocyanate (FITC) (1:200, Dianova, Germany) secondary antibodies in dark at RT for $1 \mathrm{~h}$. SC/fiber were mounted on slides using DABCO
Mowiol (Roth, Germany) and were examined using Axioimager fluorescent microscope operated with Axiovision software (Zeiss, Germany). The number of Pax7, MyoD and Myogenin positive cells/fiber and number of SC clusters/fiber were manually counted $(n=15-20$ fibers per experimental condition). Immunofluorescence for $\mathrm{C} 2 \mathrm{C} 12$ to detect the myogenic relative markers and the contractile proteins was carried out. Briefly, $\mathrm{C} 2 \mathrm{C} 12$ cells were cultivated in MD medium at a rate of $1 \times 10^{4}$ cells/well on sterile glass coverslips in 24-well culture plates for 1, 4 and 7 days under both NX and HX conditions. Immunofluorescence staining for Pax7 and MyoD was performed on day 1 and 4, while staining for Myogenin was carried out on day 7 after differentiation. The staining of MHC types was examined at day 14 following MD using mouse anti-MHC type I, MHC type IIa and MHC type IIb (1:30, DSHB) primary antibodies diluted in the blocking buffer. Nuclei were visualized using 4, 6-diamidino-2-phenylindole dihydrochloride (DAPI, ThermoFisher).

\section{Phalloidin staining}

To evaluate the effects of $\mathrm{HX}$ on the morphometric parameters of $\mathrm{C} 2 \mathrm{C} 12$ cells, $1 \times 10^{4}$ cells per well were seeded in GM on coverslips. The plates were cultivated under both experimental conditions up to day-14 postMD. The cells were fixed with $4 \%$ PFA for 10 min at RT then were washed in PBS twice for $10 \mathrm{~min}$. the cells were permeabilized in $0.1 \%$ tween (Roth, Germany) for $5 \mathrm{~min}$. After washing with PBS, the cells were incubated with $0.5 \mathrm{mg} / \mathrm{mL}$ fluorescein isothiocyanate conjugated phalloidin (Sigma-Aldrich, Germany diluted 1:30 in PBS) in dark for $30 \mathrm{~min}$. Cell nuclei were counterstained with DAPI for $5 \mathrm{~min}$. The cells were mounted with DABCO Mowiol and then were photographed under fluorescent microscope. Morphometric analysis of the myotubes indicating MD was conducted on five randomly chosen microscopic fields per experimental group $(n=6)$. The data parameters including number, length and size of the myotubes were measured using ImageJ software.

\section{Alizarin Red S staining (ARS)}

The cells induced to osteogenic lineage under NX and HX conditions up to 21 days were fixed in 4\% PFA in PBS for $10 \mathrm{~min}$ then, were washed in distilled water for 5 min, were incubated with $1 \%$ ARS ( $\mathrm{pH} 4.2)$ at RT for $10 \mathrm{~min}$ and were washed three times with distilled water for $5 \mathrm{~min}$. The mineralized matrix were examined and were photographed using the light microscope equipped with camera and LAS V4. 4 software (Leica, Germany). Semi-quantitative evaluation of ARS at days 14 and 21 was carried out. Briefly, the stained plates were washed twice with distilled water and then were incubated with $2 \mathrm{~mL}$ of $10 \%$ Cetyl Pyridinium Chloride (Roth Germany) 
for $1 \mathrm{~h}$ to elute the staining. From each experimental group $(n=6)$, a volume of $200 \mu \mathrm{L}$ was transferred to a 96-well plate in triplicates. The absorbance was detected at $562 \mathrm{~nm}$ using a microplate reader (Tecan, Germany).

\section{Oil Red O staining (ORO)}

Following adipogenic induction under NX and HX conditions up to 21 days, the cells were fixed in 4\% PFA for $10 \mathrm{~min}$, were washed in PBS and were incubated with ORO staining (Sigma-Aldrich) diluted in distilled water for $30 \mathrm{~min}$. ORO stained cells were examined and were photographed using light microscope provided with a digital camera and the LAS V4.4 operating software (Leica, Germany). Semi-quantitative analysis for adipogenic capacity of the cells was performed. Briefly, ORO stained cells were incubated with $100 \%$ isopropanol for $30 \mathrm{~min}$. A volume of $200 \mu \mathrm{L}$ from each experimental group was pipetted into a 96-well plate and the absorbance was measured at $492 \mathrm{~nm}$ in triplicates using the microplate reader. For both experimental groups, the number of adipocytes $(\mathrm{n})$, the number of fat vacuoles per adipocyte $(\mathrm{n})$ and the size of the fat vacuoles $\left(\mu \mathrm{m}^{2}\right)$ per adipocyte at days 14 and 21 were measured. Five microscopic images representing the whole well plate were analyzed using ImageJ software.

\section{RT-qPCR}

Cells induced to MD, AD and OD under both NX and HX conditions were evaluated up to 21 days post-induction. Non-induced cells kept in BM were processed in parallel, and served as negative controls. Almost $1 \mu \mathrm{g}$ RNA probes were extracted from all experimental groups using RNA purification kit (Sigma-Aldrich, Germany). RNA samples were treated with DNAse I (Roche, Germany) and then were reverse-transcribed into cDNA by using a Multiscribe ${ }^{\mathrm{TM}}$ Reverse Transcriptase (Thermo Fisher Scientific). The cyclic conditions including; $21^{\circ} \mathrm{C}$ for $8 \mathrm{~min}, 42^{\circ} \mathrm{C}$ for $15 \mathrm{~min}, 99^{\circ} \mathrm{C}$ for $5 \mathrm{~min}$, and $5{ }^{\circ} \mathrm{C}$ for $5 \mathrm{~min}$, followed by cooling step to $4{ }^{\circ} \mathrm{C}$ were applied. The harvested cDNA was incubated with Biotherm Taq Polymerase, ultrapure water, buffer, dNTP, and the relative forward and reverse primers. The primers used in the current study are random hexamers (Table 1, Microsynth, Germany). PCR was carried out for 35 cycles as follows; $5 \mathrm{~min}$ at $95^{\circ} \mathrm{C}, 30 \mathrm{~s}$ at $94{ }^{\circ} \mathrm{C}, 30 \mathrm{~s}$ at $60{ }^{\circ} \mathrm{C}, 30 \mathrm{~s}$ at $72{ }^{\circ} \mathrm{C}$, and $1 \mathrm{~min}$ at $72{ }^{\circ} \mathrm{C}$. Quantification of MD (MyoD and Myogenin), AD (peroxisome proliferator activated receptor gamma, PPARy and fatty acid-binding protein 4, FABP4), OD (osteocalcin, $O C$ and osteopontin, $O P$ ) and hypoxia inducible factor 1 alpha (HIF1 $\alpha)$ markers expression was measured in triplicate via RT-qPCR using the GoTaq qPCR Mix (Promega, Germany). A thermal cycler was operated for 2 min at $95^{\circ} \mathrm{C}, 15 \mathrm{~s}$ at $95^{\circ} \mathrm{C}, 30 \mathrm{~s}$ at $60{ }^{\circ} \mathrm{C}, 5 \mathrm{~s}$ at $60^{\circ} \mathrm{C}$, and
$5 \mathrm{~s}$ at $95^{\circ} \mathrm{C}$ for 40 cycles using Bio-Rad CFX Manager 2.1 software (Bio-Rad GmbH, Germany). $18 S 1$ was served as an endogenous reference, and the relative expression was assessed using the 2- ${ }^{\Delta \Delta C T}$ method [41].

\section{Statistical analysis}

The data were collected from three independent experiments $(n=6)$. To analyze the effect of differentiation medium (MD, $\mathrm{AD}$ and $\mathrm{OD}$ vs. $\mathrm{BM}$ ) on the number of Pax7, MyoD, Myogenin positive cells and clusters per muscle fiber at 48 and $72 \mathrm{~h}$ under both NX and HX conditions, a two-way ANOVA was performed. Evaluation of the viability of isolated $\mathrm{SC}$ following ectopic differentiation (MD, $\mathrm{AD}$ and $\mathrm{OD}$ vs. $\mathrm{BM}$ ) after two weeks under NX and HX conditions, a one-way ANOVA was carried out. To analyze the semi-quantification measurements of OD and AD staining at days 14 and 21 under both experimental conditions, a two-way ANOVA was used. To evaluate the effect of HX on the number of adipocytes as well as the number and size of fat vacuoles per adipocyte following $\mathrm{AD}$ at day 14 compared to NX culture, a two-tailed $\mathrm{t}$ test was performed. Analysis of cell viability and proliferation of $\mathrm{C} 2 \mathrm{C} 12$ on day 1,4 and 7 under both NX and HX using a two-way ANOVA was performed. To assess the number of MyoD (day1 and day4) and Myogenin (day7) positive $\mathrm{C} 2 \mathrm{C} 12$ cells under both experimental conditions, a two-way ANOVA and independent $t$ test, respectively, were carried out. To evaluate the expression of $\mathrm{MD}$ (MyoD and Myogenin at day 7), AD (PPAR $\gamma$ and FABP-4 at day 14$)$ and $O D(O C$ and $O P$ at day 21$)$ relative markers together with HIF1 $\alpha$ under both experimental conditions, a two-tailed $t$ test was performed. To examine the effect of combined MD protocol and HX condition on the morphometric parameters of the myotubes including number, length and size, a two-way ANOVA was carried out. Multiple comparisons were tested using Tukey's and Sidak's post hoc test. All the data are presented as mean \pm SEM and $p$ value $\leq 0.05$ was considered to be significant. The analyses were carried out using GraphPad Prism 7.0 (La Jolla, Canada).

\section{Results \\ Effect of combined HX and ectopic differentiation on the myogenic capacities of $\mathrm{SC}$ in their microenvironment}

A multitude of evidence demonstrated SC performance during MD under standard culture condition. However, the oxygen requirement in the cellular microenvironment is far below compared to the ordinary culture condition. Thus, optimizing the oxygen tension in the physiological niche might alter the cellular activity and impact on their regenerative potential. In order to have a more precise data to mimic the in situ condition, we have monitored 
SC multipotency not only under HX but also when the $\mathrm{SC}$ remain in contact with their mother fibers. To visualize SC activation, motility, proliferation and differentiation on top of the muscle fiber under culture condition, a live cell imaging up to $72 \mathrm{~h}$ was performed (Additional file 1: Video S1). SC identification and tracking was performed using immunohistochemistry for the specific myogenic markers; Pax7, MyoD and Myogenin up to $72 \mathrm{~h}$ (Fig. 1a-c). The data showed that HX increased the number of MyoD positive cells per fiber following $\mathrm{MD}$ $(p<0.05), \mathrm{AD}(p<0.01)$ and $\mathrm{OD}(p<0.001)$ condition at $48 \mathrm{~h}$ compared to matched cells under NX. By comparing with non-induced cells in BM, HX increased the number of MyoD positive cells adopted for MD and OD $(p<0.05)$ but not those cells undergone AD condition (Fig. 1d). The activated cells migrate along the fiber to form regenerative clusters at the target sites. By counting the number of clusters per fiber at $48 \mathrm{~h}$ demonstrated that HX regardless of the induction medium for differentiation was able to enhance cell motility and increase cluster formation along the fiber as observed under $\mathrm{BM}, \mathrm{MD}$ and $\mathrm{AD}$ $(p<0.05)$ compared to NX. The distribution of the cell clusters was even more pronounced in the presence of the OD medium $(p<0.001)$ compared to NX condition (Fig. 1e).

After $72 \mathrm{~h}, \mathrm{SC}$ tend to differentiate via down regulation of Pax7 and MyoD expression. In contrast, alternatively the expression of Myogenin was enhanced. The data showed that the number of Myogenin positive cells per fiber was higher under MD regardless of the hypoxic effect in comparison with either non-induced cells in $\mathrm{BM}(p<0.01)$ or those cells cultivated under AD and OD $(p<0.001)$ conditions. Moreover, under NX, the number of Myogenin positive cells in the presence of $\mathrm{AD}$ and OD medium was reduced $(p<0.001$ and $p<0.05)$ in comparison with non-induced cells in BM. In contrast, the Myogenin positive cells were increased under MD $(p<0.001)$ compared to those cells in BM under NX condition (Fig. 1f). Similarly, the number of SC clusters was increased in the presence of MD under HX $(p<0.05)$ compared to NX condition as the data shown at $48 \mathrm{~h}$. Unexpectedly, the number of SC clusters was increased in the OD medium under NX either in comparison with matched cells under HX $(p<0.001)$ or the non-induced cells in BM $(p<0.001)$ (Fig. $1 \mathrm{~g})$. The data revealed enhanced cell proliferation and cluster distribution under HX for all differentiation condition at $48 \mathrm{~h}$ that might suggest improved cell proliferation. Furthermore, the reduction in Myogenin positive cells following $\mathrm{AD}$ and OD compared to MD under HX at $72 \mathrm{~h}$ could be indicative for SC multipotency. The data point out that using OD medium under HX restricts SC cluster formation compared to NX culture.

\section{Effect of $\mathrm{HX}$ on quiescence and terminal differentiation of SC in their native substrate}

In order to examine whether HX modulate myogenic relative markers in the course of $\mathrm{MD}$, a double immunofluorescence to quantify Pax7 and Myogenin positive cells was carried out at $72 \mathrm{~h}$. The analysis showed that the percentage of cells positive for Myogenin following MD was less under HX $(p<0.001)$ in comparison with matched induction under NX condition. In contrast, the percentage of Pax7 positive cells was higher when MD was carried out under HX $(p<0.001)$ in comparison with NX. Regardless to the influence of the $\mathrm{O}_{2}$ concentration, no significance were detected in the percentage of Pax7 and Myogenin positive cells in BM, AD and OD between both experimental conditions (Fig. 2a, b-j). The data point out that $\mathrm{HX}$ might interfere with MD via persistent cyclic progression that maintains Pax7 expression.

\section{HX impairs myogenic differentiation and promotes the multipotency of SC in a monolayer culture}

To have an overview about the effect of long-term HX exposure on the MD and multipotency of SC, isolated SC were allowed to differentiate as monolayer in MD, $\mathrm{AD}$ and $\mathrm{OD}$ medium for up to 21 days. Evaluation of cell viability under HX pointed out marked differences in comparison with NX culture condition. The cells undergone $\mathrm{MD}, \mathrm{AD}$ and $\mathrm{OD}$ have shown reduction in cell viability already after two weeks under NX culture $(p<0.05$, $p<0.01$ and $p<0.001)$ in comparison with non-induced cells in BM. In contrast, the cells cultivated under HX demonstrated increased cell viability even in parallel with differentiation induction for all experimental groups $(p<0.01, p<0.001)$ as shown for MD, AD and OD in comparison with matched cells under NX (Fig. 3a). Morphological assessment for MD at day 7 using phalloidin staining demonstrated that HX reduces the number of myotubes formation indicative for MD $(p<0.05)$ in comparison with NX condition (Fig. 3b c, d and Additional file 2: Fig. S1a). In contrary, using AD medium, there were numerous adipocytes with larger fat vacuoles under HX in comparison with NX condition as shown for ORO staining at day 14 (Fig. 3e-g). Similarly, OD medium drives a higher matrix mineralization by calcium $\mathrm{Ca}^{2+}$ deposition as shown after ARS staining in comparison with NX condition at day 21 (Fig. $3 \mathrm{~h}-\mathrm{j}$ ). In order to confirm these histological observations, semi-quantitative analysis of the matrix mineralization and fat vacuoles formation following OD and AD induction, respectively, up to day 21 was performed. The data revealed increased $\mathrm{Ca}^{2+}$ deposition following OD at days 14 and 21 under HX $(p<0.01$ and $p<0.001)$ compared to matched condition at day 7. Moreover, promoted $\mathrm{Ca}^{2+}$ deposition under HX at day $21(p<0.001)$ compared to the same time point 


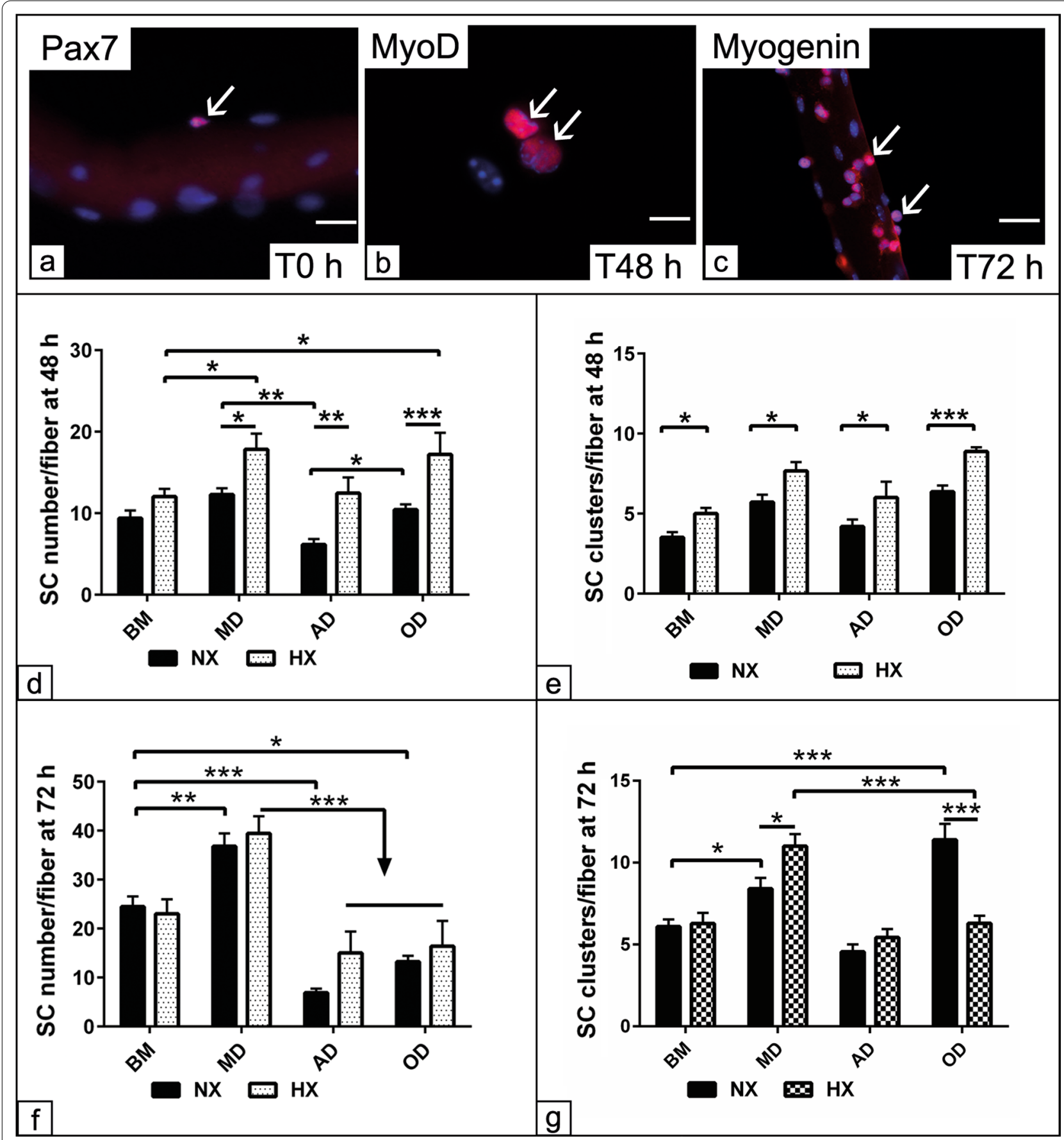

Fig. 1 Effect of combined HX and ectopic differentiation on the myogenic capacities of SC in their microenvironment. a Immunofluorescence show SC positive for Pax7 at time 0 (T0 h), b MyoD at $48 \mathrm{~h}$ (T48) and c Myogenin at $72 \mathrm{~h}$ (T72) in red. SC/fiber were cultivated in basal medium $(B M)$, myogenic differentiation (MD), adipogenic differentiation (AD) and osteogenic differentiation media up to $72 \mathrm{~h}$ under both normoxic (NX) and hypoxic (HX) culture conditions. d Quantification of the total number of MyoD positive cells per fiber ( $n=20$ fibers) at $48 \mathrm{~h}$. e Quantification of cell clusters positive for MyoD per fiber at $48 \mathrm{~h}$. $\mathbf{f}$ Quantification of the total number of cells positive for Myogenin per fiber ( $\mathrm{n}=20 \mathrm{fibers})$ at $72 \mathrm{~h}$. $\mathbf{g}$ Quantification of cell clusters positive for Myogenin per fiber at $72 \mathrm{~h}$. All data presented as mean \pm SEM. ${ }^{*} p<0.05,{ }^{* *} p<0.01,{ }^{* * *} p<0.001$. DAPI waS used as a nuclear counterstain (blue). Scale bar $=10 \mu \mathrm{M}$ 


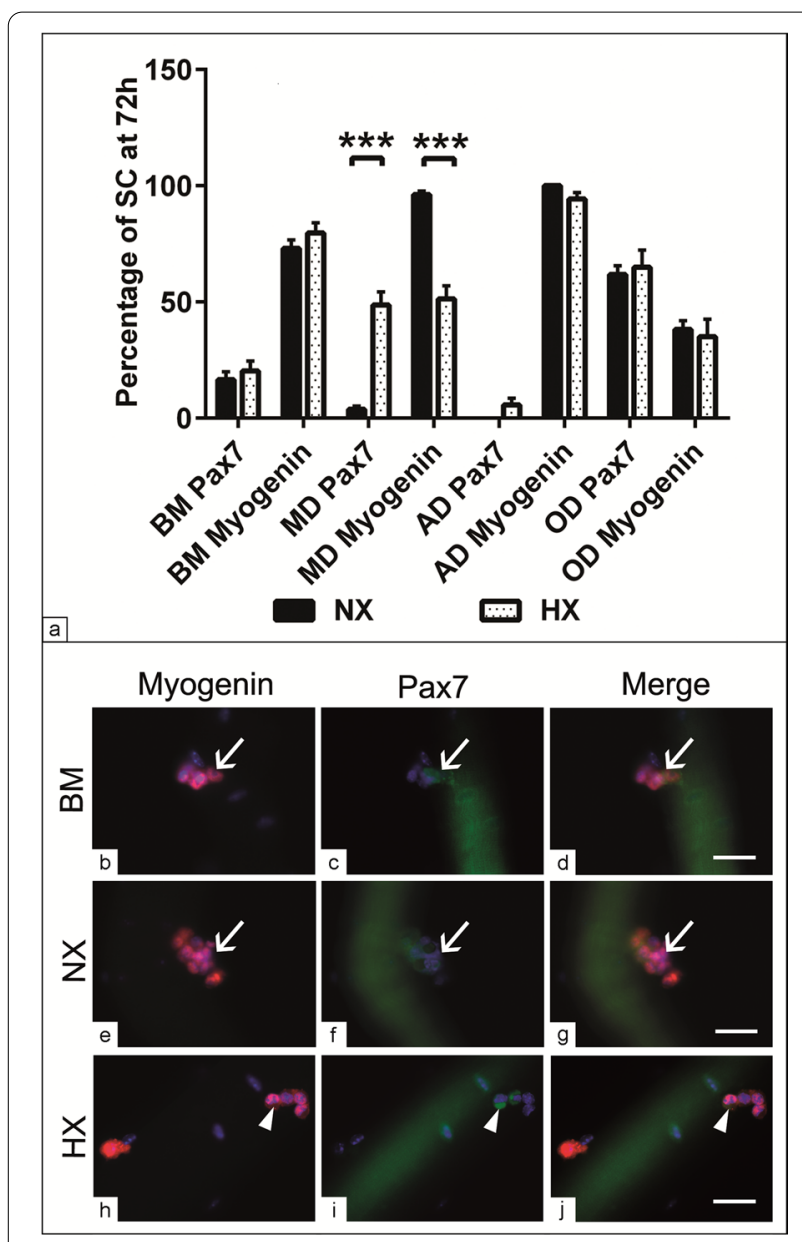

Fig. 2 Effect of $H X$ on quiescence and terminal differentiation of SC in their native substrate. $\mathbf{a}-\mathbf{j} \mathrm{SC} /$ fiber $(\mathrm{n}=15-20)$ were cultivated in $\mathrm{BM}, \mathrm{MD}, \mathrm{AD}, \mathrm{OD}$ media in 24-well culture plates in triplicate under both $\mathrm{NX}$ and $\mathrm{HX}$ conditions for $72 \mathrm{~h}$. a Average percentage of Pax7 and Myogenin positive cells per fiber at $72 \mathrm{~h}$. $\mathrm{HX}$ reduces the percentage of Myogenin positive cells and increased the percentage of Pax7 positive cells compared to NX condition. $\mathbf{b}-\mathbf{j}$ A double immunofluorescence of SC/fiber show Myogenin (red) and Pax7 (green) positive cells (arrow). Note the cells positive for Myogenin (red, arrow head) and Pax7 (green, arrow head) under HX condition at $72 \mathrm{~h}(\mathbf{h}-\mathbf{j})$. All data presented as mean \pm SEM. ${ }^{*} p<0.05,{ }^{* *} p<0.01$, ${ }^{* * *} p<0.001$. DAPI was used as a nuclear counterstain (blue). Scale bar $=10 \mu \mathrm{M}$ under HX (Additional file 2: Fig. S1b). Similarly, the analysis showed a higher AD capacity for those cells induced under HX at days 14 and 21 ( $p<0.05$ and $p<0.001)$ compared to matched cells under NX condition (Additional file 2: Fig. S1c). The morphometric analysis revealed that under HX, an increase in the number of adipocytes $(p<0.001)$ compared to those cells under NX following $\mathrm{AD}$ at day 21 (Additional file 2: Fig. S1d). Moreover, the data revealed increases in the size of the fat vacuoles per adipocyte $(p<0.01)$ but not the number of individual vacuoles per adipocyte under HX condition (Additional file 2: Fig. S1e, f).

At the molecular level, a detailed quantification for the $\mathrm{MD}, \mathrm{AD}$ and $\mathrm{OD}$ relative markers expression using RT-qPCR was carried out. Quantification of the relative mRNA revealed that $\mathrm{HX}$ upregulated $M y o D$ and $H I F 1 \alpha$ $(p<0.001, p<0.01)$ expression compared to NX condition at day7 of MD (Fig. 3k-m). In contrast, the expression of differentiation marker Myogenin was downregulated $(p<0.05)$ at the same condition under HX. On the other hand, the expression of FABP-4, PPAR $\gamma$ and HIF1 $\alpha$ were upregulated at day 14 of $\mathrm{AD}(p<0.01, p<0.05)$ under HX compared to matched cultivation in NX condition (Fig. $3 n-$ p). Similarly, the expression of osteogenic common markers was evaluated after 21 days under HX. The analysis revealed upregulated $O C, O P$ and $H I F 1 \alpha$ expression under $\mathrm{HX}(p<0.01, p<0.001)$ in comparison with the cells under NX condition (Fig. 3q-s). The data point out that although HX impaired MD alternatively, the cells were more prone to the $\mathrm{AD}$ and $\mathrm{OD}$ lineages under respective induction.

\section{Effect of $\mathrm{HX}$ on proliferation capacity and myogenic commitment of $\mathrm{C} 2 \mathrm{C} 12$}

To have a precise overview regarding the effect of HX on $\mathrm{MD}, \mathrm{C} 2 \mathrm{C} 12$ myoblasts cell line was deployed to examine cell viability and proliferation capacities as well as the efficiency of MD protocols. Analysis of cells viability up to day 7 revealed a reduced cell viability after day 1 under HX $(p<0.05)$ followed by a compensatory increases in cell viability at day 4 and day 7 either in comparison with the cells under NX $(p<0.001)$ or after day 1 of HX

\section{(See figure on next page.)}

Fig. $3 \mathrm{HX}$ impairs myogenic differentiation and promotes the multipotency of SC in a monolayer culture. a-s Skeletal muscle-derived SC were seeded $1 \times 10^{4}$ cells/well in GM for $48 \mathrm{~h}$ and then were allowed to differentiate into myogenic (MD), adipogenic (AD) and (OD) fate using relative induction medium up to 21 days under both NX and HX conditions. a Measurement of cell viability under combined differentiation medium and HX culture condition using after two weeks using MTT assay. The absorbance was measured at $570 \mathrm{~nm}$ wavelength. b-d Myotubes formation stained with phalloidin (Ph, green) at day 7 after MD. e-g Adipocytes contain fat vacuoles stained with Oil Red O (ORO, red) after two weeks of AD. $\mathbf{h}-\mathbf{j}$ Matrix mineralization stained with Alizarin Red S (ARS, red) after three weeks of OD. $\mathbf{k}-\mathbf{s}$ Quantitative RT-PCR of cells lysates show the relative expression of the MD markers; MyoD and Myogenin ( $\mathbf{k}, \mathbf{I})$ at day 7, the AD markers; FABP-4 and PPARY (n, o) at day 14 and OD markers; Osteocalcin $(O C)$ and Osteopontin $(O P, \mathbf{q}, \mathbf{r})$ at day 21 after differentiation induction. $\mathbf{m}, \mathbf{p}, \mathbf{s}$ Quantification of HIFla relative expression in the course of MD, AD and $\mathrm{OD}$ induction. Non-induced cells cultivated in parallel in basal medium (BM) were used as negative controls. All data presented as mean $\pm \mathrm{SEM}$. ${ }^{*} p<0.05,{ }^{* *} p<0.01,{ }^{* * *} p<0.001$. DAPI was used as a nuclear counterstain (b, $c, d$, blue).Scale bar in b, $c, d=100 \mu m$ and in $e-j=200 \mu m$ 


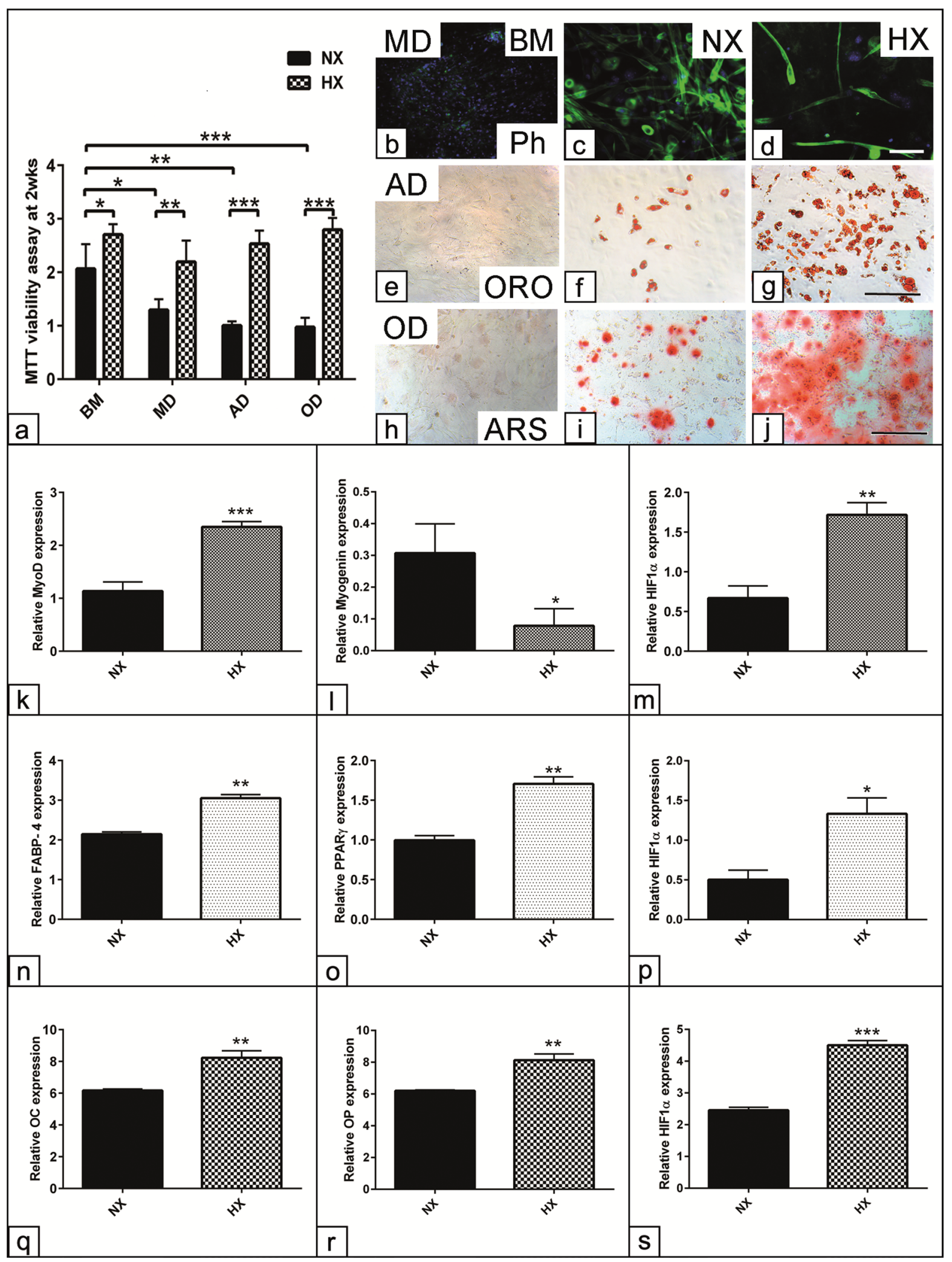

Fig. 3 (See legend on previous page.) 
$(p<0.001)$. The analysis showed a significant interaction between the effect of HX modulation and the time scale on the cell viability $(p<0.001)$ that point for alteration in the cell performance under HX (Fig. 4a). To evaluate whether enhanced cell viability under HX is due to improved metabolic activity without a real increases in the cell number or there is an increased cell proliferation. Although a reduction in the total protein contents indicative for reduction in the cell number after 1 day under HX $(p<0.01)$, an increase after day $4(p<0.001)$ could be detected in comparison with cells under NX. In contrast, cells under HX showed a lower cell number $(p<0.01)$ when compared to day 7 under NX. The analysis revealed a significant interaction $(p<0.001)$ between the effect of $\mathrm{HX}$ and the experimental time scale on the cell number (Fig. 4b). The data point for that although cells under HX showed promoted cell viability at day 7 , the cell number was even less which might suggest superior effect of HX on metabolic activity. Along the line, $\mathrm{C} 2 \mathrm{C} 12$ myoblasts were evaluated under $\mathrm{HX}$ using a colony formation assay. The analysis revealed a stable and progressive increase in the colony size indicative for cell proliferation under $\mathrm{HX}$ $(p<0.01, p<0.001$ and $p<0.001)$ at $1 \times 10^{2}, 5 \times 10^{2}$ and $1 \times 10^{3}$ seeding densities compared to NX culture condition. A double increases in the colony size at $5 \times 10^{2}$ and $1 \times 10^{3}$ seeding densities was detected under HX compared to cells under NX (Fig. 4c).

To examine the cell positivity for myogenic markers, Pax7, MyoD and Myogenin under HX, an immunofluorescence staining was conducted. The results showed no Pax7 positive cells under both experimental conditions up to day 4; however, MyoD and Myogenin positive cells were detected in both conditions (Fig. 4f-i). The analysis revealed increases in the number of MyoD positive cells at day $4(p<0.05, p<0.001)$ compared to day 1 in both NX and HX conditions, respectively. Furthermore, the number of MyoD positive cells was higher under HX at day $4(p<0.001)$ in comparison with NX at the same time point (Fig. 4d). In contrast, the number of Myogenin positive cells were significantly higher under NX at day 7 $(p<0.001)$ compared to HX (Fig. 4e).

\section{Evaluation of various protocols on MD capacity of $\mathrm{C} 2 \mathrm{C} 12$ cells under $\mathrm{HX}$ condition}

In order to assess whether HX modulate the efficiency of the MD, various protocols were carried out. Phalloidin staining demonstrated less myotube formation under HX in the presence of standard MD medium; however, combined MD medium with dexamethasone (DX) was able to increase myotube formation (Fig. 5a, b). Morphometric analysis revealed no detectable alterations in the number of myotubes for the selected protocols under NX. In contrast, a significant reduction in myotube number was observed in the presence of MD $+\operatorname{TGF} \beta(p<0.05)$ in comparison with either MD medium or MD + DX under HX conditions. Although myotube number increased using the protocol of combined MD + DX compared to MD alone, was not statistically significant (Fig. 5e). The data showed increased myotubes length $(\mu \mathrm{m})$ in the $\mathrm{MD}+\mathrm{DX}$ and $\mathrm{MD}+\mathrm{TGF} \beta$-based protocols under $\mathrm{HX}$ $(p<0.05)$ in comparison with the same protocol under NX (Fig. 5d). In order to examine whether selected protocols alter the size of the formed myotubes, the area of the individual myotubes $\left(\mu \mathrm{m}^{2}\right)$ was measured. The analysis revealed significant increases in the myotube size under HX $(p<0.05)$ when MD medium was combined with DX in comparison with either MD + ITS or MD + DX + ITSbased protocols. By combining MD medium with TGF $\beta$, no change was detected in the size of the myotube in both experimental conditions (Fig. 5c). In order to examine the presence of the contractile proteins under $\mathrm{HX}$, immunofluorescence for the common MHC in the muscles was carried out. The morphologic observation demonstrated that after 14 days under NX, few myotubes were positive for MHCI, IIa and IIb either in the presence of $\mathrm{MD}$ or $\mathrm{MD}+\mathrm{DX}$ - based protocols compared to non-induced cells in BM. In contrast, the same protocols under HX showed marked increases in the MHCI, IIa and IIb positive myotubes in comparison with both noninduced cells in BM and as well as the cells maintained under NX condition (Fig. 5f, g). No morphological difference under both $\mathrm{O}_{2}$ conditions when TGF $\beta$ was added to the MD medium (Fig. 5i).

\section{Discussion}

Cell-based therapy has received much attention in the last few decades. Optimizing the isolation, characterization and expansion procedures would increase the efficiency of stem cell for clinical applications in musculoskeletal disorders $[42,43]$. It is worth mentioning that the impaired cell viability, low survival rate and improper microenvironment significantly reduce the efficiency of stem cells for regeneration. Consequently, basic research plays a pivotal role to optimize cellular microenvironment to mimic the physiological niche. We hypothesized that low oxygen concentration to a more physiological levels would improve regeneration capacities of SC.

Our data reveal an enhanced cell viability, distribution and proliferation under HX when SC remained in contact with their own muscle fiber. The mechanism involved in promoted cell proliferation is more likely due to low $\mathrm{O}_{2}$ tension activates cell cycle-dependent molecules leading to enhanced cell proliferation and motility along the muscle fiber. In agreement with our thought, it has been reported that isolated myoblasts from aged rat showed increased cell proliferation and larger myotube under HX 


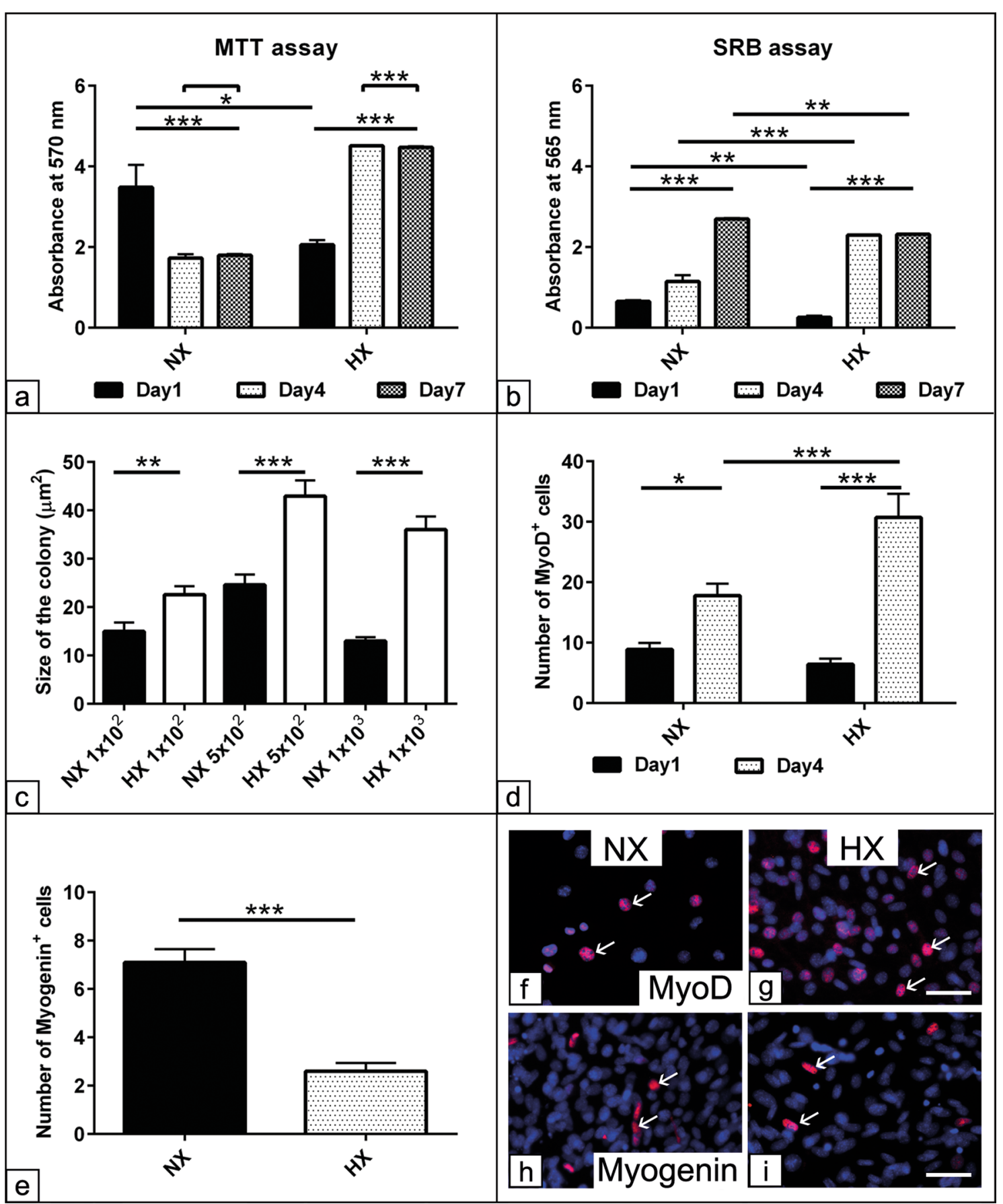

Fig. 4 Effect of $\mathrm{HX}$ on proliferation capacity and myogenic commitment of $\mathrm{C} 2 \mathrm{C} 12$. Mouse myoblasts $\mathrm{C} 2 \mathrm{C} 12$ were seeded $1 \times 10^{4} \mathrm{cells} /$ well in GM for 1, 4 and 7 days under both NX and HX conditions. a MTT assay shows cell viability up to day 7 under HX compared to NX condition. The absorbance was examined at wavelength $570 \mathrm{~nm}$. b SRB assay indicative for total protein contents reveals the cell number after days 1,4 and 7 under $\mathrm{HX}$ compared to NX condition. c Measurement of $\mathrm{C} 2 \mathrm{C} 12$ colony size $\left(\mu \mathrm{m}^{2}\right)$ at $1 \times 10^{2}, 5 \times 10^{2}$ and $1 \times 10^{3}$ seeding densities under $\mathrm{HX}$ compared to NX condition. C2C12 were seeded at various densities in GM in T-25 culture flasks ( $n=3$ per experimental group) for 7 days under both NX and HX conditions. The colonies were fixed in 4\% PFA for $10 \mathrm{~min}$ and then were stained with $5 \mathrm{mg} / \mathrm{mL}$ crystal violet in $2 \%$ ethanol for 8 min. $\mathbf{d}-\mathbf{i}$ Evaluation of the myogenic commitment of C2C12 under HX. C2C12 were seeded $1 \times 10^{4}$ cells/well in triplicates with myogenic differentiation medium up to day 7 under both NX and HX conditions. $\mathbf{d}$ Number of MyoD positive cells after day- 1 and day-4 post-induction. $\mathbf{e}$ Number of Myogenin positive cells at day-7 post-induction. $\mathbf{f}-\mathbf{i}$ Representative immunofluorescence shows MyoD (red) and Myogenin (red) positive cells (arrow) after 3 days under both NX and HX conditions. All data presented as mean \pm SEM. ${ }^{*} p<0.05,{ }^{* *} p<0.01,{ }^{* * *} p<0.001$. DAPI was used as a nuclear counterstain (blue). Scale bar $=20 \mu \mathrm{M}$ 
in comparison with the standard culture condition [44]. A similar study has shown that neural stem cells have a higher proliferation and survival rate under $\operatorname{HX}[45,46]$. We believe that HX causes intracellular molecular adaptations to overcome lack of $\mathrm{O}_{2}$ tension. In the same line, it was found that the level of G1/S cyclins and cyclindependent kinases was increased and the level of cell cycle inhibitor p27 was decreased together with elevated Akt phosphorylation under HX up to $72 \mathrm{~h}$ [28]. This is in consistent with the downregulation of Myogenin under $\mathrm{HX}$ as shown in our data suggesting that HX might interfere with the cell withdrawal from the cyclic proliferation. An important report revealed that HX inhibits the expression of the MD molecules via blocking the expression of cell cycle-dependent kinase inhibitor p21 and p27 in addition, it prevents the product of the retinoblastoma gene leading to a failure of cell cycle withdrawal and terminal differentiation. Furthermore, HX promotes MyoD degradation which prevents the recruitment of the differentiation marker [33]. In agreement with this hypothesis, it has been documented that under $0.5-2 \% \mathrm{O}_{2}$ level, $M y o D$ expression was transiently blocked causing a delayed Myogenin expression in $\mathrm{C} 2 \mathrm{C} 12$ myoblasts, the author concluded that HX induction initiates a transient acetylation of the $M y o D$ promotor [47].

The data revealed that the number of Myogenin positive cells was decreased to the control level when $\mathrm{AD}$ and OD medium was used that might indicate inhibition of MD alternatively, induction of AD and OD fates. Surprisingly, the number of clusters per fiber in the presence of OD was higher under NX compared to HX. However, the possible explanation that cell viability criteria including activation and motility along the fibers was suppressed under combined HX exposure together with OD induction elements. The other possibility that under combined HX and OD medium, the cells showed a robust activation of the OD that might restrict the cell clustering along the fibers and impair their motility.

The results revealed an increased number of Pax7 positive cells after $72 \mathrm{~h}$ under HX. These data could point out that HX promotes SC proliferation rather than terminates the myogenic differentiation. In this respect, it was found that HX enhances the stemness properties that facilitates the in vitro reproducibility of muscle progenitors before further therapeutic applications [44]. Under HX, SC undergo symmetric division that facilitates selfrenewal and quiescence rather than an asymmetric division toward MD. Such mechanism is modulated by Notch signaling via inhibiting miR-1 and miR-206 activities through canonical Hes/Hey proteins causing increases in Pax7 expression [48]. Similarly, by using a myogenic cell lineage overexpressing Notch, it was found that Pax7 was directly regulated via Notch expression that leads to promoted self-renewal of SC [49]. Along this line of argumentation, using human SC for tissue engineering constructs has revealed that $\mathrm{HX}$ condition improves the myogenic proliferation capacity via upregulations of Pax7, Myf5 and MyoD expression, while it maintains the quiescence properties of the SC population [50]. It is worth mention that $\mathrm{HX}$ recruits myoblasts transition from differentiation to proliferation by decreasing p38 phosphorylation in the differentiating cells [51]. Our data suggest that the cells lose Pax7 at later passage in $\mathrm{C} 2 \mathrm{C} 12$ (P8-9) additionally used in the present study. In the same line, it has been reported although quiescent cells and proliferating myoblasts express Pax7, proliferating cells downregulate Pax7 expression after a certain round of multiplication [52].

Cultivation of the $\mathrm{C} 2 \mathrm{C} 12$ myoblasts under HX revealed a transient reduction after $24 \mathrm{~h}$ followed by promoted cell viability up to day 4 . The initial reduction in the cell viability under HX could be an adaptational mechanism to compensate the lack of oxygen. This finding is partially in accordance with a previous report indicating that the proliferation of humans myoblasts was slightly lower under $5 \% \mathrm{O}_{2} \mathrm{HX}$, whereas the cell proliferation become higher under HX at later time points compared to NX [53]. Similar studies have revealed that HX enhances the proliferation of mouse primary isolated myoblasts [30], bovine myoblasts [29], rat primary isolated myoblasts [31] and human myoblasts [53]. These data suggest that HX might enhance the metabolic activity of stem cells leading to a higher viability even without a comparable increase in cell number as shown at day 7 . This

\footnotetext{
(See figure on next page.)

Fig. 5 Evaluation of various protocols on MD capacity of $\mathrm{C} 2 \mathrm{C} 12$ cells under $\mathrm{HX}$ condition. $\mathrm{C} 2 \mathrm{C} 12$ were seeded $1 \times 10^{4}$ cells/well in GM for $48 \mathrm{~h}$ then were differentiated into myogenic fate using only standard myogenic differentiation (MD) medium or using combined MD medium together with dexamethasone (MD + DX), MD + TGF $\beta, M D$ + ITS and MD + DX + ITS for 14 days under both NX and HX conditions. $\mathbf{a}$, b C2C12 cells stained with phalloidin actin filaments stain (green) show myotubes formation indicative for myogenic differentiation after day 7 under NX and $H X$ conditions. Combined MD + DX based protocol enhances myogenic differentiation in comparison with either MD or MD +TGF $\beta$. Non-induced cells cultivated in parallel in basal medium (BM) were used as negative controls. c-e Morphometric analysis reveals the size $\left(\mu m^{2}, c\right)$, length ( $\mu m$, $\left.d\right)$ and number $(n, e)$ of the myotubes per microscopic field $(n=10)$ following myogenic differentiation for 7 days using MD, MD $+D X, M D+T G F \beta, M D+I T S$ and $\mathrm{MD}+\mathrm{DX}+\mathrm{ITS}$-based protocols under both $\mathrm{NX}$ and $\mathrm{HX}$ conditions. $\mathbf{f}-\mathbf{i}$ Immunofluorescence of C2C12 cells show MHCl, MHClla, and MHCllb positive myotubes (red) after differentiated in MD (g), MD + DX (h) and MD + TGF $\beta$ (i)-based protocols under both NX and HX conditions. Non-induced cells cultivated in parallel in basal medium (BM) were used as negative controls (f). All data presented as mean \pm SEM. ${ }^{*} p<0.05,{ }^{* *} p<0.01,{ }^{* * *} p<0.001$. DAPI was used as a nuclear counterstain (blue). Scale bar $=20 \mu \mathrm{M}$
} 


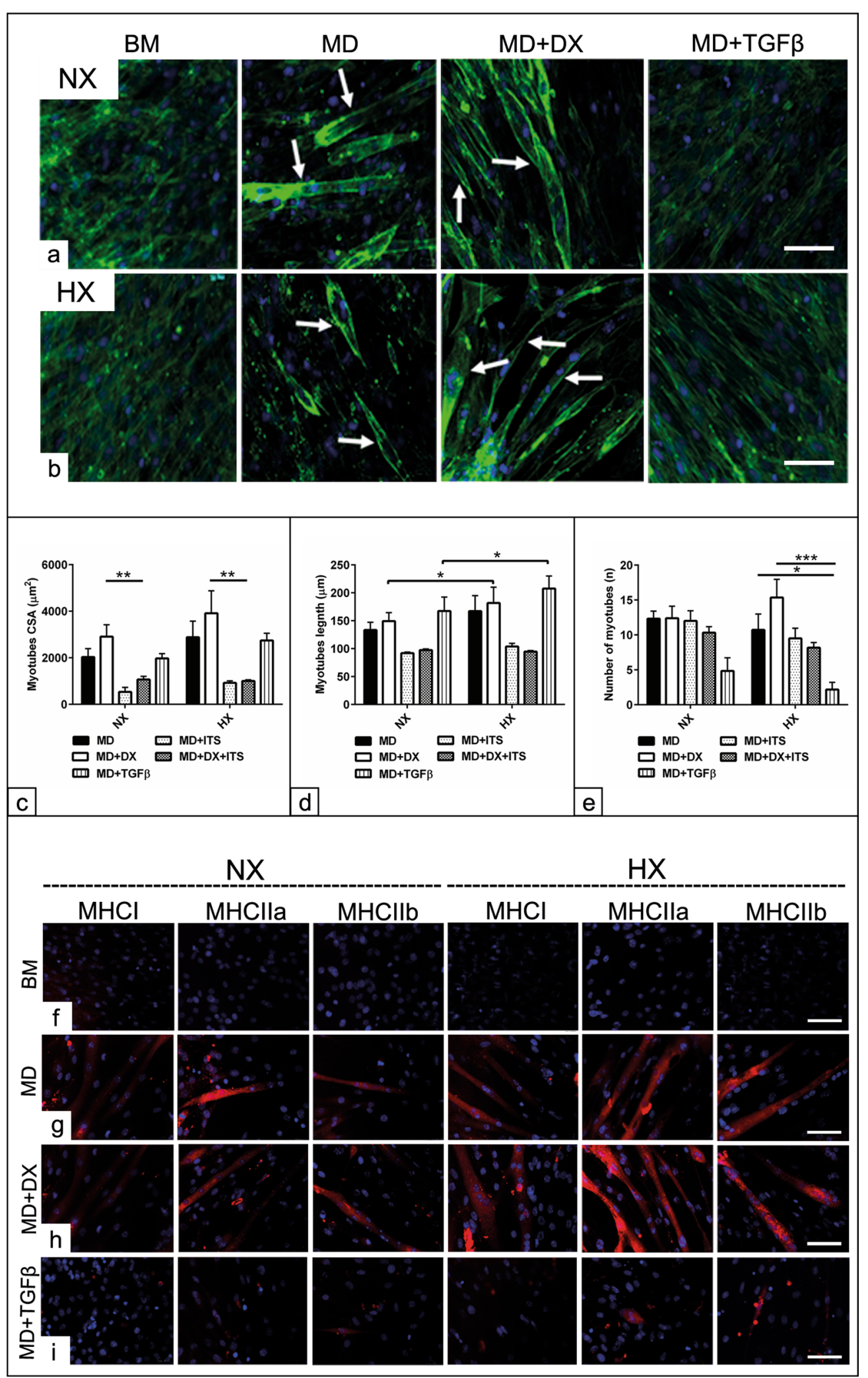

Fig. 5 (See legend on previous page.) 
phenomenon could be a crucial prerequisite to improve the regenerative ability of stem cell.

The enhanced proliferative capacity of $\mathrm{C} 2 \mathrm{C} 12$ under $\mathrm{HX}$ in terms of a stable and progressive increases in the colony size indicating the positive effect on cell viability at various seeding densities. These data suggest that HX enhanced the proliferation ability of the individual cells to form larger colonies compared to $\mathrm{NX}$ as previously reported in rat [44] and in human myoblasts [27]. We believe that quiescent $\mathrm{SC}$ require low $\mathrm{O}_{2}$ level for their maintenance in an in vivo microenvironment, thus the effect of HX would support their quiescence. Along the line, a study concluded that SC express Hypoxia inducible factor $2 A$ (HIF2A) which promotes their quiescence and prevent the MD via a mechanism including Spry 1 gene activation by HIF2A. The inhibition of HIF2A improves the regenerative capacity via enhanced cell proliferation and differentiation which might have a therapeutic value to promote muscle regeneration [54]. In the present study, a $3 \% \mathrm{O}_{2}$ level was sufficient to observe an enhanced cell viability in $\mathrm{C} 2 \mathrm{C} 12$ cells; however, below this, threshold might have a toxic or damaging effect to the cells. It was found that severe $\mathrm{HX}\left(1 \% \mathrm{O}_{2}\right)$ level impaired myoblast function due to aberrant epigenetic modulation of the autophagy including dephosphorylation of Glycogen synthase kinase $3 \beta($ GSK $3 \beta)$ and inactivation of Notch signaling [55].

Multipotential induction under HX revealed a reduction in myogenic differentiation capacity. In agreement with our results, it was reported that myotube formation by $\mathrm{C} 2 \mathrm{C} 12$ myoblasts cultured in differentiation medium for 3 days was lower under HX compared to NX conditions [29]. Similarly, neither myotube formation nor MHC expression could be detected in $\mathrm{C} 2 \mathrm{C} 12$ cells and in the L6E9 rat myoblast cultured in a differentiation medium for 1 and 2 days under HX [33]. Our data are in agreement with previous report explaining the suppressive effect of HX on MD. It was found that HX upregulates histone deacetylases (HDACs) causing impaired myogenesis [55]. In the same line, lack of $\mathrm{O}_{2}$ inhibits protein synthesis as well as signaling including the phosphatidylinositol 3-kinase (PI3K)/AKT/mTOR pathway that plays a role to maintain MyoD1 stability and translation via mammalian target of rapamycin1 (mTOR1) activation [51]. Additionally, the modulated PI3K/AKT signaling was due to sensitivity of insulin-like growth factor receptor (IGFIR) to $\mathrm{O}_{2}$ deprivation [56].

For technical reason, there was a limited capacity to cultivate SC/ fiber for more than $72 \mathrm{~h}$. Alternatively, long-term $\mathrm{HX}$ condition has been applied on isolated $\mathrm{SC}$ as monolayer culture to monitor AD and OD events. The data point out that SC are more liable for AD under $\mathrm{HX}$ as the data revealed increases in the number of adipocytes and the size of fat vacuoles per adipocytes. Similarly, the enhanced OD under HX as shown by semiquantitative analysis of ARS staining. These data could be an adaptive mechanism of SC to compensate a lack of oxygen tension. A large body of evidence suggest that $\mathrm{O}_{2}$ concentration modulates the cell differentiation fate including adipogenesis, chondrogenesis and neural differentiation $[46,57,58]$. Moreover, a study has revealed the hypoxic nature of the local microenvironment within the adipose tissue in obese mice supporting our data [59]. Interestingly, it was found that $\mathrm{HX}$ induction promotes osteogenic differentiation via HIF-1-dependent mechanism in bone marrow-derived mesenchymal stem cells (MSCs) in humans suggesting their potential benefit for bone regeneration [60]. As our data shown, HIF1 $\alpha$ was upregulated in the course of AD and OD under HX condition which suggest that HIF-1 $\alpha$ mediates SC multipotency via modulation of energy metabolism and perhaps angiogenesis to counteract the effect of local ischemia. In the same line, a recent study concluded that upregulation of HIF2 expression in the adipocytes drives adipogensis in white fat in contrast, lack of its expression in brown fat enhances glucose tolerance in vivo in mice [61]. In the present study, the cells were exposed to continuous HX up to 21 days. A similar study investigating the effect of cyclic HX on OD in mesenchymal stem cells revealed an improvement of bone condition with ageing due to the inhibition of bone resorption and enhanced mineral density [62]. In the same line, similar study comparing the adipogenic and osteogenic capacities of both compact bone and bone marrow MSCs reported that although both cell populations revealed similar adipogenic ability, compact bone-derived MSCs showed a superior osteogenic capacity under HX [63]. Furthermore, it has been reported that HX enhances vascular endothelial growth factor (VEGF) and interleukin 6 (IL6) expression as well as it coordinates stem cells homing and mobilization [64]. Along the line, using biomaterials scaffold incorporated with HX inducing agents (Desferoxamine) to enhance OD of adipose tissue-derived mesenchymal stem cells reported the efficiency of scaffolds to upregulate $H I F 1 \alpha$ and $V E G F$ expression and to improve OD in humans [65].

The data revealed a positive effect of supplementing the MD medium with dexamethasone under HX on the MD. Recent study concluded that dexamethasone enhances muscle regeneration in mice via improving the kinesin-1 motor activity that plays a central role to stimulate myogenic contractile elements expression, myoblasts fusion and formation of polarized myotubes [66]. The time of dexamethasone treatment either before myogenic induction or after the onset of myotubes might be a critical approach for the outcome. It was found that treatment 
with dexamethasone after differentiation produced a thinner myotube as well as decreased MHC proteins. In contrast, treatment with dexamethasone before the differentiation not only increased the number and size of myotubes, but also the level of MHC proteins [67]. Myogenesis can adapt to hypoxic conditions; a report revealed that although $\mathrm{MD}$ of $\mathrm{C} 2 \mathrm{C} 12$ myoblasts was repressed after day 3 under $0.5 \% \mathrm{O}_{2}$, an extensive $\mathrm{MD}$ was detected up to day 12 [47]. The present data revealed that the enhanced MD with dexamethasone was blocked by adding ITS suggesting a suppressive effect on MD. A report revealed that glucocorticoids showed anti-adipogenic and pro-myogenic activities that promote the terminal myogenic differentiation; such effect was glucocorticoids receptor-dependent [68]. In contrast, combined MD together with TGF $\beta$ inhibits MD under HX. In agreement with our data, it has been found that myoblasts releases Myostatin, a member of TGF $\beta$ superfamily under HX which interrupts the negative feedback effect leads to inhibition of cell proliferation and enhances muscle growth [69]. Furthermore, the overexpression of Myostatin reduces the expression of MyoD1 [70] via AKT signaling pathway inhibition [71].

\section{Conclusion}

The present study elucidated the effect of HX on MD of SC. The data revealed that under HX an enhanced cell proliferation, cell motility along the fiber and promoted SC quiescence as well as an impairment of MD. The increased multipotency of SC under HX as shown by enhanced adipogenesis and osteogenesis suggests that targeting HX could be beneficial to improve bone regeneration. The negative effect of $\mathrm{HX}$ on the MD was improved by adding dexamethasone to the MD medium. Altogether, the data provide a closer look to the regenerative and multipotential abilities of the myogenic precursors using two culture model to mimic the in vivo and in vitro regeneration under HX. We provide evidence that $3 \% \mathrm{HX}$ exposure might be beneficial to improve stem cell reproducibility before transplantation also considering HX induction to promote SC multipotency.

\footnotetext{
Abbreviations

SC: Skeletal muscle-derived stem cells; C2C12: Mouse myoblasts cell line; NX: Normoxic condition; HX: Hypoxic condition; MHC: Myosin heavy chain; MD: Myogenic differentiation; AD: Adipogenic differentiation; OD: Osteogenic differentiation; BM: Basal medium; GM: Growth medium; RT: Room temperature; DX: Dexamethasone; Pax7: Paired Box 7; MRF4: Myogenic regulatory factor 4; TGF $\beta$ : Transforming growth factor beta; ITS: Insulin-transferrin-sodium selenite; PPARY: peroxisome proliferator activated receptor gamma; FABP4: fatty acidbinding protein 4; OC: Osteocalcin; OP: osteopontin; HIFla: Hypoxia inducible factor 1 alpha; HIF2A: Hypoxia inducible factor 2A; GSK3 $\beta$ : Glycogen synthase kinase 3ß; HDACs: Histone deacetylases; mTOR1: Mammalian target of rapamycin 1; IGFIR: Insulin-like growth factor receptor; VEGF: Vascular endothelial growth factor; IL6: Interleukin 6; DAPI: 4,6-Diamidino-2-phenylindole dihydrochloride; SRB:
}

Sulforhodamine B; MTT: (3-(4, 5-Dimethylthiazol-2-yl)-2, 5-Dimethyltetrazolium Bromide) cell viability assay; PFA: Paraformaldehyde.

\section{Supplementary Information}

The online version contains supplementary material available at https://doi. org/10.1186/s13287-022-02730-5.

\begin{abstract}
Additional file 1: Video S1. Monitoring SC on top of the muscle fiber under standard culture condition. Live cell imaging shows SC activation, motility, proliferation and differentiation on top of the muscle fiber under culture condition.

Additional file 2: Fig. 1. Quantification of multipotential induction of SC under HX condition. SC were seeded $1 \times 104$ cells/well $(n=6$ per experimental condition) in GM for $48 \mathrm{~h}$ then, were kept in myogenic differentiation (MD) medium contained $4.5 \mathrm{~g} / \mathrm{L}$ glucose DMEM supplemented with $2 \%$ horse serum, $2.5 \mathrm{ng} / \mathrm{mL}$ human Fibroblast Growth Factor, $1 \%$ Sodium pyruvate up to 14 days; adipogenic differentiation medium (AD) composed of $4.5 \mathrm{mg} / \mathrm{mL}$ glucose DMEM supplemented with $5 \% \mathrm{FCS}, 1 \mu \mathrm{M}$ dexamethasone, $5 \mu \mathrm{g} / \mathrm{mL}$ Insulin-transferrin-selenium and $5 \mu \mathrm{M}$ Rosiglitazone and osteogenic differentiation medium (OD) contained $1 \mathrm{mg} / \mathrm{mL}$ glucose DMEM supplemented with 5\% FCS, $0.1 \mu \mathrm{M}$ dexamethasone, $250 \mu \mathrm{M}$ ascorbic acid, and $10 \mathrm{mM} \beta$-glycerophosphate up to 21 days under both NX and HX conditions. Non-induced cells kept in basal medium (BM) containing 5\% FCS in DMEM were considered controls (a) Number of myotubes per microscopic field $(n=5)$ show reduced myotubes formation under $\mathrm{HX}$. (b) Semi-quantification of Alizarin Red $\mathrm{S}$ staining shows increased $\mathrm{Ca}+2$ deposition under $\mathrm{HX}$ indicative for OD after 14 and 21 days. (c) Semi-quantification of Oil Red O staining shows enhanced AD after 14 and 21 days. (d) Number of adipocytes per microscopic field $(n=5)$ reveals increases of AD under HX. (e) Number of fat vacuoles per adipocyte shows no changes under HX. (f) Measurement of fat vacuoles per adipocyte shows increases of the individual vacuoles size $(\mu \mathrm{m} 2)$ under HX. All data presented as mean \pm SEM. ${ }^{*}=p<0.05,{ }^{* *}=$ $p<0.01,{ }^{* * *}=p<0.001$.
\end{abstract}

\section{Acknowledgements}

We thank the Education, Audiovisual and Culture Executive Agency of the European Commission for partially funding the project in the framework of the Erasmus Mundus Master Program EUCOMOR. Further thanks given to Manuela Heimann, Eva Kammer, Kathrin Wolf-Hofmann and Susanne Schubert-Porth for technical support.

\section{Authors' contributions}

MIE, MK and MCK and AE have collected the raw data set, analyzed the results and wrote the original draft of the manuscript. SW and SA have interpreted the results and revised the submitted version of the manuscript. All authors have read and approved the manuscript.

Funding

Open Access funding enabled and organized by Projekt DEAL.

Availability of data and materials

The data collected and the analysis performed to generate the manuscript results are available from the corresponding author on reasonable request.

\section{Declarations}

\section{Ethics approval and consent to participate}

All the standard procedures were approved by Justus-Liebig-University of Giessen and the local authorities (RP Giessen) regarding animal care and use.

\section{Consent for publication}

Not applicable.

\section{Competing interests}

All the authors have declared no conflict of interest regarding the publication of this article. 


\section{Author details}

${ }^{1}$ Institute of Veterinary Anatomy, Histology and Embryology, Justus-LiebigUniversity of Giessen, Frankfurter Str. 98, 35392 Giessen, Germany. ${ }^{2}$ Clinic of Small Animals, c/o Institute of Veterinary Anatomy, Histology and Embryology, Justus Liebig University of Giessen, 35392 Giessen, Germany. ${ }^{3}$ Anatomy and Embryology Department, Faculty of Veterinary Medicine, University of Mansoura, Mansoura 35516, Egypt.

Received: 1 November 2021 Accepted: 20 January 2022 Published online: 05 February 2022

\section{References}

1. Mauro A. Satellite cell of skeletal muscle fibers. J Biophys Biochem Cytol. 1961;9:493-5. https://doi.org/10.1083/jcb.9.2.493.

2. Bareja A, Billin AN. Satellite cell therapy_from mice to men. Skelet Muscle. 2013;3:2. https://doi.org/10.1186/2044-5040-3-2.

3. Tabebordbar M, Wang ET, Wagers AJ. Skeletal muscle degenerative diseases and strategies for therapeutic muscle repair. Annu Rev Pathol. 2013;8:441-75. https://doi.org/10.1146/annurev-pathol-011811-132450.

4. Prevalence of Duchenne/Becker muscular dystrophy among males aged 5-24 years - four states, 2007. MMWR Morb Mortal Wkly Rep. 2009;58:1119-22.

5. Muir LA, Chamberlain JS. Emerging strategies for cell and gene therapy of the muscular dystrophies. Expert Rev Mol Med. 2009;11:e18. https://doi. org/10.1017/S1462399409001100.

6. Partridge TA. Impending therapies for Duchenne muscular dystrophy. Curr Opin Neurol. 2011;24:415-22. https://doi.org/10.1097/WCO.0b013 e32834aa3f1.

7. Galli F, Bragg L, Meggiolaro L, Rossi M, Caffarini M, Naz N, et al. Gene and cell therapy for muscular dystrophies: are we getting there? Hum Gene Ther. 2018;29:1098-105. https://doi.org/10.1089/hum.2018.151.

8. Brignier AC, Gewirtz AM. Embryonic and adult stem cell therapy. J Allergy Clin Immunol. 2010;125:S336-44. https://doi.org/10.1016/j.jaci.2009.09. 032.

9. Fortier LA, Travis AJ. Stem cells in veterinary medicine. Stem Cell Res Ther. 2011;2:9. https://doi.org/10.1186/scrt50.

10. Volk SW, Theoret C. Translating stem cell therapies: the role of companion animals in regenerative medicine. Wound Repair Regen. 2013;21:382-94. https://doi.org/10.1111/wrr.12044.

11. Markoski MM. Advances in the use of stem cells in veterinary medicine: from basic research to clinical practice. Scientifica (Cairo). 2016;2016:4516920. https://doi.org/10.1155/2016/4516920.

12. Hosoyama T, van Dyke J, Suzuki M. Applications of skeletal muscle progenitor cells for neuromuscular diseases. Am J Stem Cells. 2012;1:253-63.

13. Maclean S, Khan WS, Malik AA, Anand S, Snow M. The potential of stem cells in the treatment of skeletal muscle injury and disease. Stem Cells Int. 2012;2012: 282348. https://doi.org/10.1155/2012/282348.

14. Said RS, Mustafa AG, Asfour HA, Shaqoura El. Myogenic satellite cells: biological milieu and possible clinical applications. Pak J Biol Sci. 2017;20:111. https://doi.org/10.3923/pjbs.2017.1.11.

15. Kang J-S, Krauss RS. Muscle stem cells in developmental and regenerative myogenesis. Curr Opin Clin Nutr Metab Care. 2010;13:243-8. https://doi. org/10.1097/MCO.0b013e328336ea98.

16. Zammit PS. All muscle satellite cells are equal, but are some more equal than others? J Cell Sci. 2008;121:2975-82. https://doi.org/10.1242/jcs. 019661.

17. Kuang S, Gillespie MA, Rudnicki MA. Niche regulation of muscle satellite cell self-renewal and differentiation. Cell Stem Cell. 2008;2:22-31. https:// doi.org/10.1016/j.stem.2007.12.012.

18. Grefte S, Kuijpers-Jagtman AM, Torensma R, von den Hoff JW. Skeletal muscle development and regeneration. Stem Cells Dev. 2007;16:857-68. https://doi.org/10.1089/scd.2007.0058.

19. Buckingham M. Skeletal muscle progenitor cells and the role of Pax genes. C R Biol. 2007;330:530-3. https://doi.org/10.1016/j.crvi.2007.03. 015.

20. Le Grand F, Rudnicki MA. Skeletal muscle satellite cells and adult myogenesis. Curr Opin Cell Biol. 2007;19:628-33. https://doi.org/10.1016/j.ceb. 2007.09.012.
21. Jang YC, Sinha M, Cerletti M, Dall'Osso C, Wagers AJ. Skeletal muscle stem cells: effects of aging and metabolism on muscle regenerative function. Cold Spring Harb Symp Quant Biol. 2011;76:101-11. https://doi.org/10. 1101/sqb.2011.76.010652.

22. Yin $H$, Price F, Rudnicki MA. Satellite cells and the muscle stem cell niche. Physiol Rev. 2013;93:23-67. https://doi.org/10.1152/physrev.00043.2011.

23. Musarò A. The basis of muscle regeneration. Adv Biol. 2014;2014:1-16 https://doi.org/10.1155/2014/612471.

24. Berardi E, Sampaolesi M. Novel therapeutic approaches for skeletal muscle dystrophies. In: Sakuma K, editor. Muscle cell and tissue. London: IntechOpen; 2015. https://doi.org/10.5772/60479.

25. Asakura A, Komaki M, Rudnicki M. Muscle satellite cells are multipotential stem cells that exhibit myogenic, osteogenic, and adipogenic differentiation. Differentiation. 2001;68:245-53. https://doi.org/10.1046/j.1432-0436. 2001.680412.x.

26. Florini JR, Magri KA. Effects of growth factors on myogenic differentiation. Am J Physiol. 1989;256:C701-11. https://doi.org/10.1152/ajpcell.1989. 256.4.C701.

27. Sellathurai J, Nielsen J, Hejbøl EK, Jørgensen LH, Dhawan J, Nielsen MFB, Schrøder HD. Low oxygen tension enhances expression of myogenic genes when human myoblasts are activated from G0 arrest. PLoS ONE. 2016;11:e0158860. https://doi.org/10.1371/journal.pone.0158860.

28. Li X, Zhu L, Chen X, Fan M. Effects of hypoxia on proliferation and differentiation of myoblasts. Med Hypotheses. 2007;69:629-36. https://doi.org/ 10.1016/j.mehy.2006.12.050.

29. Kook S-H, Son Y-O, Lee K-Y, Lee H-J, Chung W-T, Choi K-C, Lee J-C. Hypoxia affects positively the proliferation of bovine satellite cells and their myogenic differentiation through up-regulation of MyoD. Cell Biol Int. 2008;32:871-8. https://doi.org/10.1016/j.cellbi.2008.03.017.

30. Urbani L, Piccoli M, Franzin C, Pozzobon M, de Coppi P. Hypoxia increases mouse satellite cell clone proliferation maintaining both in vitro and in vivo heterogeneity and myogenic potential. PLoS ONE. 2012;7:e49860. https://doi.org/10.1371/journal.pone.0049860.

31. Lees SJ, Childs TE, Booth FW. p21(Cip1) expression is increased in ambient oxygen, compared to estimated physiological (5\%) levels in rat muscle precursor cell culture. Cell Prolif. 2008;41:193-207. https://doi.org/10. 1111/j.1365-2184.2008.00512.x.

32. Carreau A, El Hafny-Rahbi B, Matejuk A, Grillon C, Kieda C. Why is the partial oxygen pressure of human tissues a crucial parameter? Small molecules and hypoxia. J Cell Mol Med. 2011;15:1239-53. https://doi.org/ 10.1111/j.1582-4934.2011.01258.x.

33. Di Carlo A, de Mori R, Martelli F, Pompilio G, Capogrossi MC, Germani A. Hypoxia inhibits myogenic differentiation through accelerated MyoD degradation. J Biol Chem. 2004;279:16332-8. https://doi.org/10.1074/jbc. M313931200

34. Keire P, Shearer A, Shefer G, Yablonka-Reuveni Z. Isolation and culture of skeletal muscle myofibers as a means to analyze satellite cells. Methods Mol Biol. 2013;946:431-68. https://doi.org/10.1007/978-1-62703-128-8_ 28.

35. Pasut A, Jones AE, Rudnicki MA. Isolation and culture of individual myofibers and their satellite cells from adult skeletal muscle. J Vis Exp. 2013. https://doi.org/10.3791/50074.

36. Elashry MI, Gaertner K, Klymiuk MC, Eldaey A, Wenisch S, Arnhold S. Characterisation of stemness and multipotency of ovine muscle-derived stem cells from various muscle sources. J Anat. 2021. https://doi.org/10.1111/ joa. 13420 .

37. Elashry MI, Heimann M, Wenisch S, Patel K, Arnhold S. Multipotency of skeletal muscle stem cells on their native substrate and the expression of Connexin 43 during adoption of adipogenic and osteogenic fate. Acta Histochem. 2017;119:786-94. https://doi.org/10.1016/j.acthis.2017.10. 002.

38. Yaffe D, Saxel O. Serial passaging and differentiation of myogenic cells isolated from dystrophic mouse muscle. Nature. 1977;270:725-7. https:// doi.org/10.1038/270725a0.

39. Blau HM, Pavlath GK, Hardeman EC, Chiu CP, Silberstein L, Webster SG, et al. Plasticity of the differentiated state. Science. 1985;230:758-66. https://doi.org/10.1126/science.2414846.

40. Orellana EA, Kasinski AL. Sulforhodamine B (SRB) assay in cell culture to investigate cell proliferation. Bio Protoc. 2016. https://doi.org/10.21769/ BioProtoc. 1984. 
41. Schmittgen TD, Livak KJ. Analyzing real-time PCR data by the comparative C(T) method. Nat Protoc. 2008;3:1101-8. https://doi.org/10.1038/ nprot.2008.73.

42. Barton-Davis ER, Shoturma DI, Musaro A, Rosenthal N, Sweeney HL. Viral mediated expression of insulin-like growth factor I blocks the aging-related loss of skeletal muscle function. Proc Natl Acad Sci U S A. 1998;95:15603-7. https://doi.org/10.1073/pnas.95.26.15603.

43. Heslop L, Morgan JE, Partridge TA. Evidence for a myogenic stem cell that is exhausted in dystrophic muscle. J Cell Sci. 2000;113(Pt 12):2299-308.

44. Chakravarthy MV, Spangenburg EE, Booth FW. Culture in low levels of oxygen enhances in vitro proliferation potential of satellite cells from old skeletal muscles. Cell Mol Life Sci. 2001;58:1150-8. https://doi.org/10. 1007/PL00000929.

45. Morrison SJ, Csete M, Groves AK, Melega W, Wold B, Anderson DJ. Culture in reduced levels of oxygen promotes clonogenic sympathoadrenal differentiation by isolated neural crest stem cells. J Neurosci. 2000;20:73706. https://doi.org/10.1523/JNEUROSCI.20-19-07370.2000.

46. Studer L, Csete M, Lee S-H, Kabbani N, Walikonis J, Wold B, McKay R. Enhanced proliferation, survival, and dopaminergic differentiation of CNS precursors in lowered oxygen. J Neurosci. 2000;20:7377-83. https://doi. org/10.1523/JNEUROSCI.20-19-07377.2000.

47. Yun Z, Lin Q, Giaccia AJ. Adaptive myogenesis under hypoxia. Mol Cell Biol. 2005;25:3040-55. https://doi.org/10.1128/MCB.25.8.3040-3055.2005.

48. Liu W, Wen Y, Bi P, Lai X, Liu XS, Liu X, Kuang S. Hypoxia promotes satellite cell self-renewal and enhances the efficiency of myoblast transplantation. Development. 2012;139:2857-65. https://doi.org/10.1242/dev.079665.

49. Wen Y, Bi P, Liu W, Asakura A, Keller C, Kuang S. Constitutive Notch activation upregulates Pax7 and promotes the self-renewal of skeletal muscle satellite cells. Mol Cell Biol. 2012;32:2300-11. https://doi.org/10.1128/ MCB.06753-11.

50. Koning M, Werker PMN, van Luyn MJA, Harmsen MC. Hypoxia promotes proliferation of human myogenic satellite cells: a potential benefactor in tissue engineering of skeletal muscle. Tissue Eng Part A. 2011;17:1747-58. https://doi.org/10.1089/ten.tea.2010.0624.

51. Ren H, Accili D, Duan C. Hypoxia converts the myogenic action of insulinlike growth factors into mitogenic action by differentially regulating multiple signaling pathways. Proc Natl Acad Sci USA. 2010;107:5857-62. https://doi.org/10.1073/pnas.0909570107.

52. Motohashi N, Asakura A. Molecular regulation of muscle satellite cell selfrenewal. J Stem Cell Res Ther. 2012. https://doi.org/10.4172/2157-7633. S11-e002.

53. Martin SD, Collier FM, Kirkland MA, Walder K, Stupka N. Enhanced proliferation of human skeletal muscle precursor cells derived from elderly donors cultured in estimated physiological (5\%) oxygen. Cytotechnology. 2009;61:93-107. https://doi.org/10.1007/s10616-009-9247-3.

54. Xie L, Yin A, Nichenko AS, Beedle AM, Call JA, Yin H. Transient HIF2A inhibition promotes satellite cell proliferation and muscle regeneration. J Clin Invest. 2018;128:2339-55. https://doi.org/10.1172/JC196208.

55. Zhang Z, Zhang L, Zhou Y, Li L, Zhao J, Qin W, et al. Increase in HDAC9 suppresses myoblast differentiation via epigenetic regulation of autophagy in hypoxia. Cell Death Dis. 2019;10:552. https://doi.org/10. 1038/s41419-019-1763-2.

56. Majmundar AJ, Skuli N, Mesquita RC, Kim MN, Yodh AG, Nguyen-McCarty M, Simon MC. O(2) regulates skeletal muscle progenitor differentiation through phosphatidylinositol 3-kinase/AKT signaling. Mol Cell Biol. 2012;32:36-49. https://doi.org/10.1128/MCB.05857-11.

57. Schipani E, Ryan HE, Didrickson S, Kobayashi T, Knight M, Johnson RS. Hypoxia in cartilage: HIF-1alpha is essential for chondrocyte growth arrest and survival. Genes Dev. 2001;15:2865-76. https://doi.org/10.1101/gad. 934301

58. Yun Z, Maecker HL, Johnson RS, Giaccia AJ. Inhibition of PPARY2 gene expression by the HIF-1-regulated gene DEC1/Stra13. Dev Cell. 2002;2:331-41. https://doi.org/10.1016/s1534-5807(02)00131-4.

59. Hosogai N, Fukuhara A, Oshima K, Miyata Y, Tanaka S, Segawa K, et al. Adipose tissue hypoxia in obesity and its impact on adipocytokine dysregulation. Diabetes. 2007:56:901-11. https://doi.org/10.2337/db06-0911.

60. Wagegg M, Gaber T, Lohanatha FL, Hahne M, Strehl C, Fangradt M, et al. Hypoxia promotes osteogenesis but suppresses adipogenesis of human mesenchymal stromal cells in a hypoxia-inducible factor-1 dependent manner. PLoS ONE. 2012;7:e46483. https://doi.org/10.1371/journal.pone. 0046483.
61. DiStefano MT, Roth Flach RJ, Senol-Cosar O, Danai LV, Virbasius JV, Nicoloro SM, et al. Adipocyte-specific Hypoxia-inducible gene 2 promotes fat deposition and diet-induced insulin resistance. Mol Metab. 2016;5:1149-61. https://doi.org/10.1016/j.molmet.2016.09.009.

62. Camacho-Cardenosa M, Quesada-Gómez JM, Camacho-Cardenosa A, Leal A, Dorado G, Torrecillas-Baena B, Casado-Díaz A. Effects of normobaric cyclic hypoxia exposure on mesenchymal stem-cell differentiation-pilot study on bone parameters in elderly. World J Stem Cells. 2020;12:1667-90. https://doi.org/10.4252/wjsc.v12.i12.1667.

63. Rossetti R, Rós FA, de Souza LEB, Maçonetto JdM, Costa PNMd, Ferreira FU, et al. Hypoxia-cultured mouse mesenchymal stromal cells from bone marrow and compact bone display different phenotypic traits. Exp Cell Res. 2021;399:112434. https://doi.org/10.1016/j.yexcr.2020.112434.

64. Das R, Jahr H, van Osch GJVM, Farrell E. The role of hypoxia in bone marrow-derived mesenchymal stem cells: considerations for regenerative medicine approaches. Tissue Eng Part B Rev. 2010;16:159-68. https://doi. org/10.1089/ten.TEB.2009.0296.

65. Zheng X, Zhang X, Wang Y, Liu Y, Pan Y, Li Y, et al. Hypoxia-mimicking 3D bioglass-nanoclay scaffolds promote endogenous bone regeneration. Bioact Mater. 2021;6:3485-95. https://doi.org/10.1016/j.bioactmat.2021. 03.011.

66. Lin J-W, Huang Y-M, Chen Y-Q, Chuang T-Y, Lan T-Y, Liu Y-W, et al. Dexamethasone accelerates muscle regeneration by modulating kinesin1-mediated focal adhesion signals. Cell Death Discov. 2021;7:35. https:// doi.org/10.1038/s41420-021-00412-4

67. Han D-S, Yang W-S, Kao T-W. Dexamethasone treatment at the myoblast stage enhanced C2C12 Myocyte differentiation. Int J Med Sci. 2017;14:434-43. https://doi.org/10.7150/ijms.18427.

68. Cerquone Perpetuini A, Giuliani G, Reggio A, Cerretani M, Santoriello M, Stefanelli R, et al. Janus effect of glucocorticoids on differentiation of muscle fibro/adipogenic progenitors. Sci Rep. 2020;10:5363. https://doi. org/10.1038/s41598-020-62194-6.

69. Hayot M, Rodriguez J, Vernus B, Carnac G, Jean E, Allen D, et al. Myostatin up-regulation is associated with the skeletal muscle response to hypoxic stimuli. Mol Cell Endocrinol. 2011;332:38-47. https://doi.org/10.1016/j. mce.2010.09.008

70. Langley B, Thomas M, Bishop A, Sharma M, Gilmour S, Kambadur R. Myostatin inhibits myoblast differentiation by down-regulating MyoD expression. J Biol Chem. 2002;277:49831-40. https://doi.org/10.1074/jbc. M204291200

71. Lee SJ, MCPherron AC. Regulation of myostatin activity and muscle growth. Proc Natl Acad Sci USA. 2001;98:9306-11. https://doi.org/10. 1073/pnas.151270098.

\section{Publisher's Note}

Springer Nature remains neutral with regard to jurisdictional claims in published maps and institutional affiliations.

Ready to submit your research? Choose BMC and benefit from

- fast, convenient online submission

- thorough peer review by experienced researchers in your field

- rapid publication on acceptance

- support for research data, including large and complex data types

- gold Open Access which fosters wider collaboration and increased citations

- maximum visibility for your research: over $100 \mathrm{M}$ website views per year

At BMC, research is always in progress.

Learn more biomedcentral.com/submissions 